\title{
An experimental study on defrosting performance for an air source heat pump unit with a horizontally installed multi-circuit outdoor coil
}

\author{
SONG Mengjie, ${ }^{\mathrm{a}, \mathrm{b}}$, DENG Shiming ${ }^{\mathrm{b}}$, MAO Ning ${ }^{\mathrm{c}, *}$ YE Xianming $^{\mathrm{d}}$ \\ ${ }^{\text {a }}$ Guangdong Provincial Key Laboratory on Functional Soft Condensed Matter, School of Materials and \\ Energy, Guangdong University of Technology, Guangzhou, Guangdong, China \\ ${ }^{\mathrm{b}}$ Department of Building Services Engineering, The Hong Kong Polytechnic University, Hong Kong \\ Special Administration Region \\ ${ }^{c}$ College of Pipeline and Civil Engineering, China University of Petroleum (East China), Qingdao, \\ Shandong, China \\ ${ }^{\mathrm{d}}$ Department of Electrical, Electronic and Computer Engineering, University of Pretoria, Pretoria, South \\ Africa
}

*Corresponding author. MAO Ning

Tel/Fax: +86 (0) 532-86981822; E-mail address: maoning@upc.edu.cn

\section{Highlights}

- Negative effects due to gravity eliminated when outdoor coil horizontally installed.

- Defrosting efficiency increased $9.8 \%$ after outdoor coil horizontally installed.

- Defrosting efficiency decreased $6.6 \%$ when air fan reversed to blow the melted frost.

- Total mass of the retained water collected decreased $222 \mathrm{~g}$ less after wind blowing.

- Higher DEV respected better defrosting performance for multi-circuit outdoor coils. 


\begin{abstract}
When frost forms and accumulates over the outdoor coil's surface in an air source heat pump (ASHP) unit, system operating performance will be dramatically deteriorated. Reverse cycle defrosting is the most widely used standard defrosting method. A previous related study reported that downwards flowing of melted frost due to gravity over a vertical multi-circuit outdoor coil would decrease the reverse cycle defrosting performance. If the outdoor coil can be changed to horizontally installed, the flow path of melted frost over coil surface can be shortened, and the flow directions of refrigerant and melted frost changed from opposite to orthogonal. Consequently, a better defrosting performance is expected. In this paper, therefore, an experimental study on defrosting performance for an ASHP unit with a horizontally installed multi-circuit outdoor coil was conducted. Experimental results show that, when a vertical outdoor coil was changed to horizontally installed, the defrosting efficiency increased $9.8 \%$, however, with the same defrosting duration at $186 \mathrm{~s}$. Furthermore, when the outdoor air fan was reversed to blowing the melted frost during defrosting, the total mass of the retained water collected decreased $222 \mathrm{~g}$. However, the defrosting efficiency was not increased, but decreased 6.6\% because of the heat transfer enhanced between hot coil and cold ambient air.
\end{abstract}

Keywords: Air source heat pump; Defrosting; Experiment; Multi-circuit; Horizontally installed 


\section{Introduction}

As the worldwide electricity demand and price growing [1-3], environmental aspects represent a large concern and heavily influence the global energy policy, such as global warming, ozone layer depletion and high-levels of pollution, especially the PM 2.5 air pollution in Beijing in China. It is necessary to emphasize the use of emerging and well-known renewable energy, and different energy conservation approaches. Air source heat pump (ASHP) unit, utilizing low grade energy in the air as sources, has advantages of simple operation, high efficiency, no pollution, ability of both cooling and heating, etc. [4]. Accordingly, as a key type technology under clean development mechanism (CDM) to mitigate the climate change and avoid global warming [5], it becomes widely used as cooling and heating sources for heating, ventilation and air conditioning over the recent decades [6]. However, on its heating mode of an ASHP unit under extremely cold and high humidity environment, unexpected frost would appear and accumulate over the outdoor coil's airside surface, which severely deteriorates system operating performance. Therefore, it is necessary to implement periodical defrosting to maintain its normal operation.

Currently, there are many defrosting methods investigated for ASHP units, such as (1) compressor shut-down defrosting [7], (2) electric heating defrosting [8], (3) hot water spray defrosting [9], (4) ultrasonic vibration defrosting [10], (5) air-particle jet defrosting [11], and (6) hot gas by-pass defrosting [12], among which the most widely used standard defrosting method is reverse cycle defrosting [13]. When an ASHP unit is operated at a 
reverse cycle defrosting mode, its outdoor coil which is usually installed vertically for floor space saving, acts as a condenser and its indoor coil as an evaporator. On the other hand, in order to minimize the refrigerant pressure loss along the tube inside and enhance the heat transfer between the inside refrigerant and outside ambient air via tube and fins, multi-circuit outdoor coil is usually used in ASHP units. The downwards flowing melted frost helps form or reinforces a water layer between the frost and the coil surface, which introduces a thermal resistance [14], and thus reduces the heat transfer between the two [15]. It is reported that when defrosting at the top circuits is terminated, the bottom ones are still covered with frost [16]. Also, when the tube surface temperature at exit of the top circuit reaches the pre-set defrosting termination temperature, the temperature of the bottom circuit is much lower [17-20]. Thereafter, the negative effects of downwards flowing melted frost due to gravity are demonstrated by authors [17-19], with water collecting trays installed between circuits to improve defrosting efficiency $[17,18]$.

On identification of the negative effects of downwards flowing melted frost, traditional vertical multi-circuit outdoor coil is also suggested to be installed horizontally to reduce the flow path of melted frost during defrosting [21]. As shown in Figs. 1(a) and 1(b), when the vertically installed three-circuit outdoor coil [18] is horizontally installed, the maximum flow path of melted frost over coil surface can be shortened from $500 \mathrm{~mm}$ to $44 \mathrm{~mm}$, being reduced 11.36 times. As illustrated in Figs. 1 (c) and 1 (d), the flow directions of hot refrigerant and cold melted frost during defrosting are also changed from opposite to orthogonal, which effectively shortened their heat transfer length. Consequently, a better defrosting performance is expected. However, it is found that 


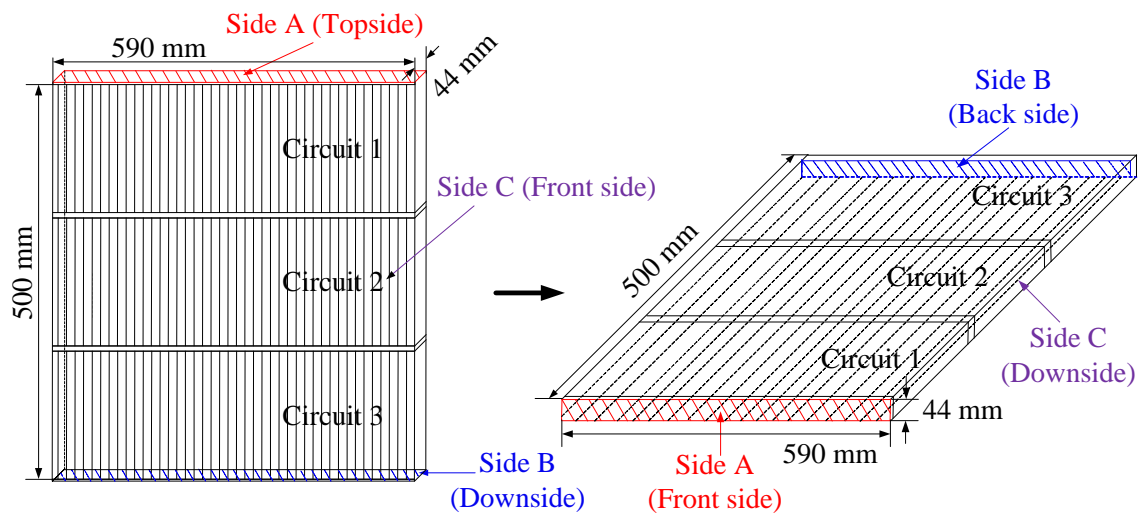

(a) Vertically installed three-circuit outdoor coil (b) Horizontally installed three-circuit outdoor coil

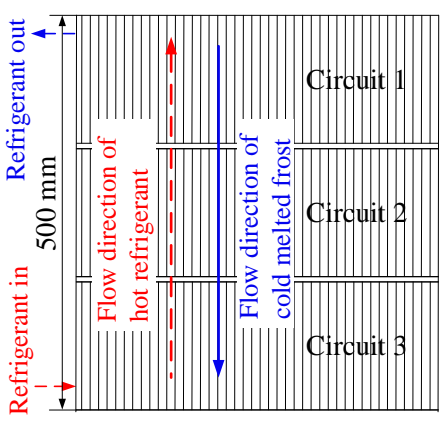

(c) Opposite flow directions

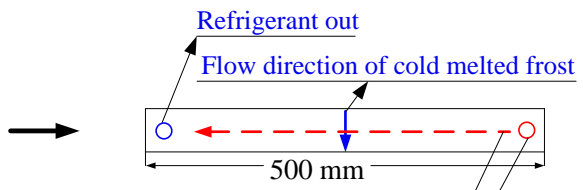

Flow direction of hot refrigerant

Refrigerant in

(d) Orthogonal flow directions

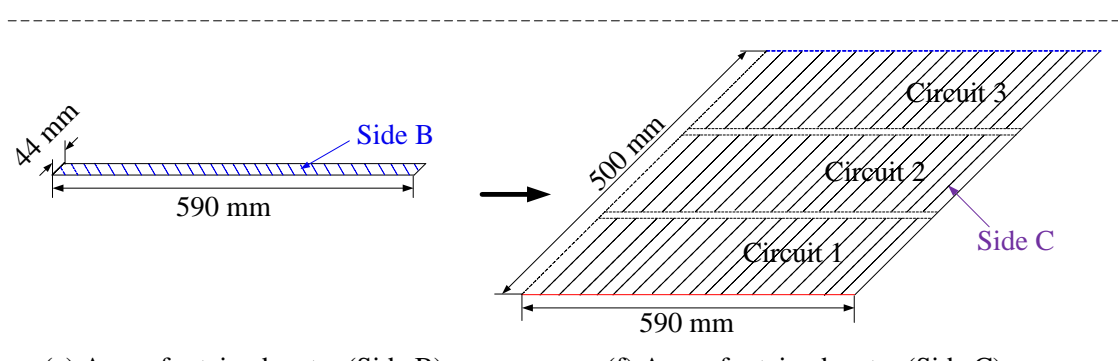

(e) Area of retained water (Side B)

(f) Area of retained water (Side C)

Fig. 1 The vertically installed three-circuit outdoor coil changed to horizontally installed

there was some melted frost remained on the downside of each circuit due to surface tension during defrosting in the previous experimental studies [17-19]. From the definition of surface tension [22], it is concluded that the total mass of retained water is directly proportional to the total area of circuit downsides. During defrosting, the retained water would consume energy [23], and thus delay the defrosting process. As shown in Figs. 1(e) and 1(f), when the installation type of the three-circuit outdoor coil is changed, 
the total area of retained water is increased, from $590 \mathrm{~mm} \times 44 \mathrm{~mm}$ to $590 \mathrm{~mm} \times 500 \mathrm{~mm}$, being increased 11.36 times. Therefore, it is contradictory for the maximum flow path of melted frost and the total area of remained water on improving system defrosting performance.

On the other hand, although horizontal heat exchangers are reported by many studies [9, 24-29], few of them are related to a coiled heat exchanger. Most of them are horizontal ground heat exchangers $[25,26]$, tube heat exchangers [27, 28], or flat-panel heat exchangers $[9,29]$. Notably, Abdel-Wahed RM et al. experimentally studied a horizontal flat plated cooling surface. Their results indicate that the decrease in the thickness of frost layer is approximately linear with defrosting time [9]. However, it is not reverse cycle defrosting, but hot water defrosting. Later, Hambraeus et al. carried out an experimental setup with a horizontal evaporator to study the heat transfer of a special refrigerant, with the effects of melted frost neglected [30]. In 2012, an experimental study on comparison of heat transfer and pressure drop in a horizontal and vertical helically coiled heat exchanger with $\mathrm{CuO} /$ water based nano fluids was reported, in which, convective heat transfer coefficient and friction factors are comparatively studied. However, their heat transfer performance on the airside was also neglected [24].

Therefore, in this paper, to solve the previous contradictory problem and explore the heat transfer performance of a horizontally installed heat exchanger, an experimental study on reverse cycle defrosting performance for an ASHP unit with a horizontal multi-circuit outdoor coil has been carried out. Firstly, the ASHP unit under experiments is presented, 
followed by the experimental procedures and conditions. Thereafter, the experimental cases and their results are given. The defrosting durations and energy consumptions for each case study are measured and discussed, with a conclusion given at the end.

\section{Experimentation}

\subsection{Experimental ASHP unit}

An experimental ASHP unit was specifically established for carrying out the experimental work reported in this paper. It was modified from a commercially available $6.5 \mathrm{~kW}$ heating-capacity variable speed ASHP unit and was installed in an existing environmental chamber having a simulated indoor heated space and a simulated outdoor frosting space. The sizes of both indoor and outdoor spaces were each measured at $3.8 \mathrm{~m}$ $(\mathrm{L}) \times 3.8 \mathrm{~m}(\mathrm{~W}) \times 2.8 \mathrm{~m}(\mathrm{H})$. Fig. 2 shows the schematics of the ASHP unit installed in the environmental chamber. The experimental ASHP unit was a split-type one consisting of a swing type compressor, an accumulator, a four-way valve, an electronic expansion valve, an indoor coil and an outdoor coil. 


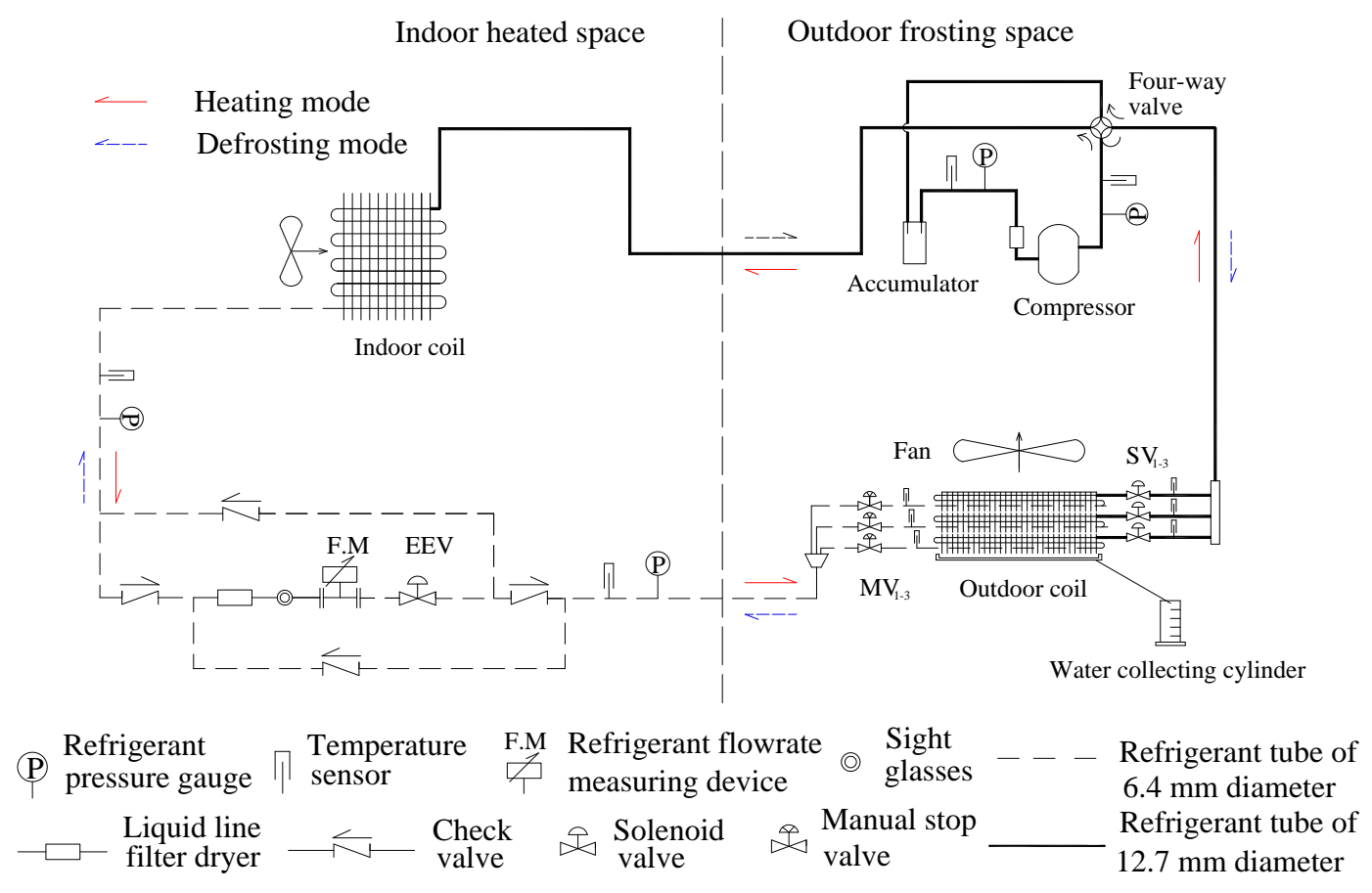

Fig. 2 Schematics of the experimental ASHP unit installed in an environmental chamber

The outdoor coil was specially designed and made for this study, as shown in Fig. 3. There were three individual and parallel refrigerant circuits and the airside surface areas corresponding to each of the three circuits were equal. There were four wind boards installed on the two air sides of the outdoor coil, which were used to prevent the air passing the outdoor coil through separations between circuits. The outdoor coil was horizontally installed, and in each circuit a solenoid valve (SV) and a manual stop valve (MV) were fixed on, with their locations shown in Fig. 3. In order to easily describe the process of frost melting, the topside and downside of the primary vertically installed three-circuit outdoor coil were named as Side A and Side B, as shown in Figs. 1 and 3. Side $\mathrm{C}$ was the inlet air side of the outdoor coil, where the frost will be formed and accumulated. 


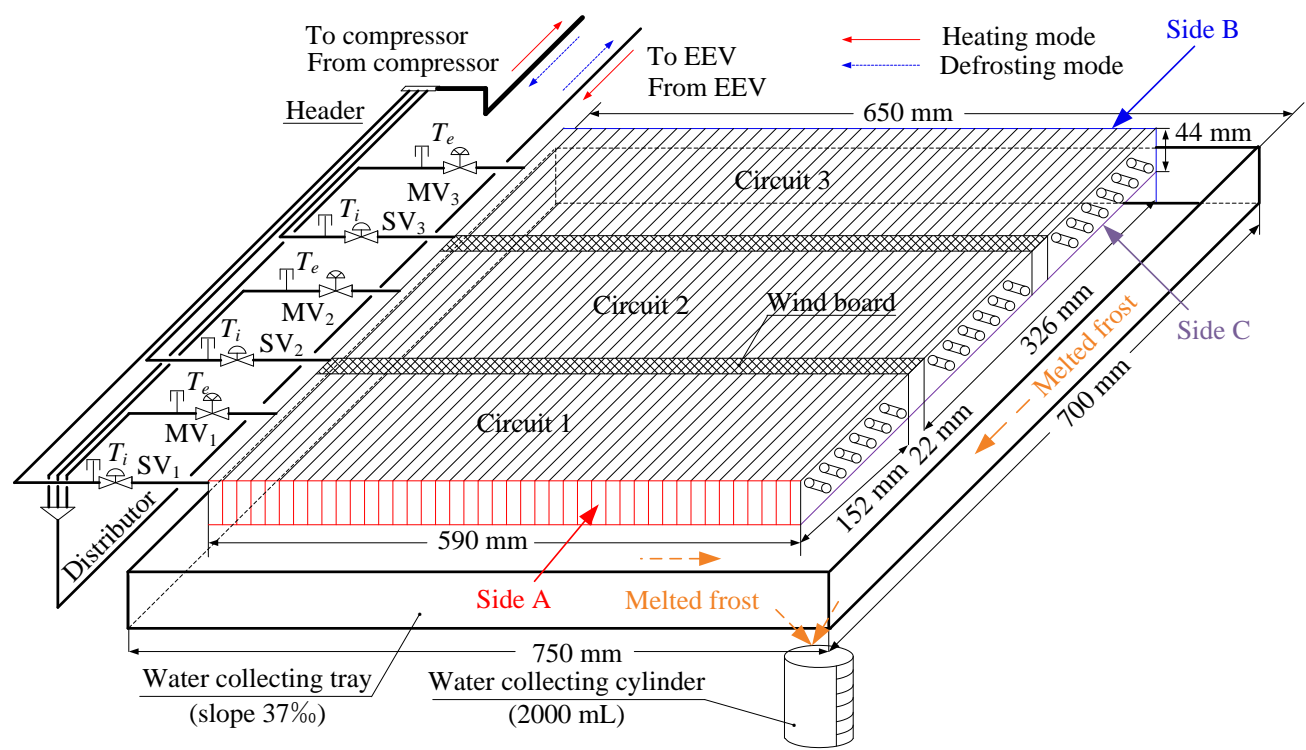

Fig. 3 Details of the horizontally installed three-circuit outdoor coil and locations of solenoid valves (SV) and manual stop valves (MV)

A $700 \mathrm{~mm} \times 750 \mathrm{~mm}$ water collecting tray made of PVC placed under the outdoor coil was added to the experiment rig, and a 2,000 $\mathrm{mL}$ water collecting cylinder made of PVC was connected to the tray. Both of them would be used for collecting and measuring the melted frost. At the same time, in the experiments, the retained water on the surface of fins, especially on the downside of each circuit, was absorbed by pre-weighed cotton tissues. In this way, the melted frost from the outdoor coil during defrosting was collected and weighed. The specifications of the three-parallel refrigerant circuit outdoor coil are shown in Table 1. 
Table 1 Specifications of the outdoor coil in the experimental ASHP unit

\begin{tabular}{|c|c|c|c|}
\hline Item & Parameter & Value & Unit \\
\hline 1 & Height of the outdoor coil & 44 & $\mathrm{~mm}$ \\
\hline 2 & Width of the outdoor coil & 590 & $\mathrm{~mm}$ \\
\hline 3 & Length of the outdoor coil & 500 & $\mathrm{~mm}$ \\
\hline 4 & Fin height & 44 & $\mathrm{~mm}$ \\
\hline 5 & Fin width & 152 & $\mathrm{~mm}$ \\
\hline 6 & Fin thickness & 0.115 & $\mathrm{~mm}$ \\
\hline 7 & Fin pitch & 2.1 & $\mathrm{~mm}$ \\
\hline 8 & Fin type & Plate & - \\
\hline 9 & Tube external diameter & 10 & $\mathrm{~mm}$ \\
\hline 10 & Tube thickness & 0.5 & $\mathrm{~mm}$ \\
\hline 15 & Tube spacing & 20 & $\mathrm{~mm}$ \\
\hline 11 & Circuit pitch & 22 & $\mathrm{~mm}$ \\
\hline 12 & Number of tube rows & 2 & - \\
\hline 13 & Number of circuits & 3 & - \\
\hline 14 & Number of water collecting tray & 1 & - \\
\hline 15 & Number of water collecting cylinder & 1 & - \\
\hline 16 & Number of wind board & 2 & - \\
\hline 17 & Material of tube & Copper & - \\
\hline 19 & Material of fin & Aluminum & - \\
\hline 20 & Material of water collecting tray & PVC & - \\
\hline 21 & Material of water collecting cylinder & PVC & - \\
\hline 22 & Material of wind board & Wood & \\
\hline 23 & Volume of water collecting cylinder & 2,000 & $\mathrm{~mL}$ \\
\hline
\end{tabular}


As shown in Fig. 4, there was a separate air conditioning system in the environmental chamber, and sensible and latent load generating units (LGUs) which were used to simulate thermal load, so that suitable experimental conditions in both indoor and outdoor spaces may be maintained. During normal heating (frosting) operation, a frosting environment in the outdoor space was maintained by running the experimental ASHP unit and LGUs together, while an indoor heated environment by the experimental ASHP unit and the existing air conditioning system.

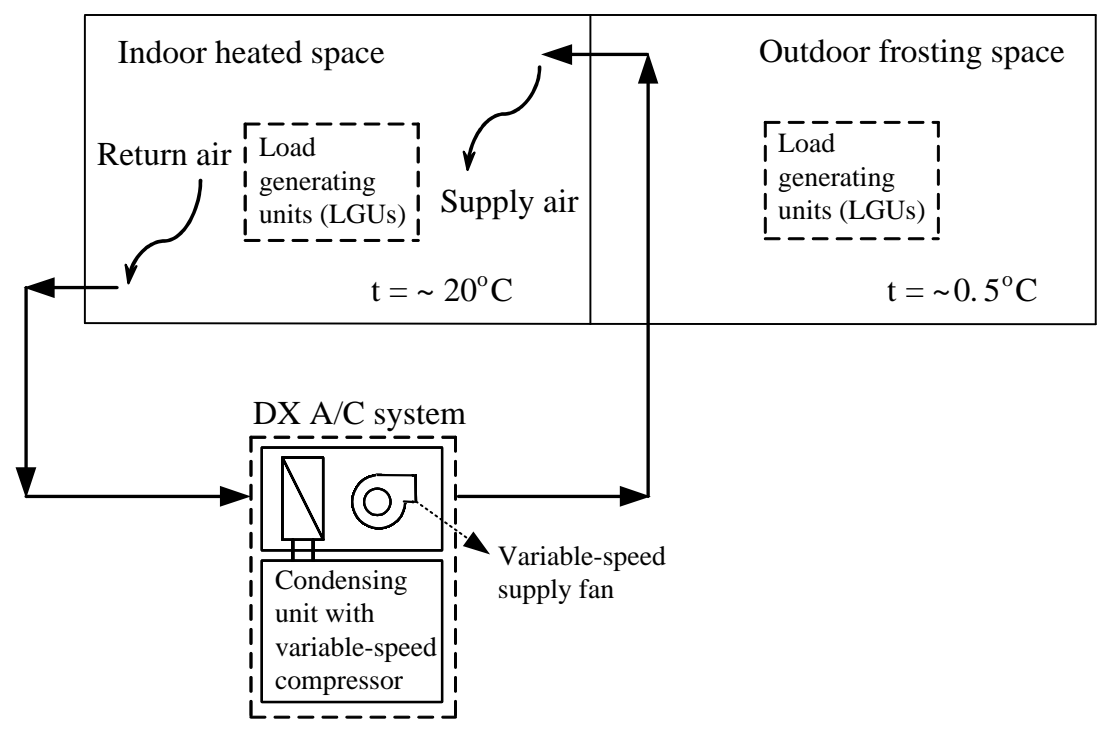

Fig. 4 The schematic diagram of the environmental chamber

Fig. 5 shows the airside details of outdoor coil in the experimental ASHP unit installed in the outdoor frosting space. On the windward side (Side $\mathrm{C}$ in Figs. 1, 3 and 5), air dry-bulb temperatures were measured at 6 points using thermocouples (Type K, of $\pm 0.75 \%$ accuracy) and air wet-bulb temperatures at 3 points using temperature sensors (PT100, class A). In this way, there were 2 dry-bulb temperature sensors and 2 wet-bulb temperature sensors for each circuit. As seen in Fig. 5, they were placed at the same 
positions for each circuit. The average values from these measurements were used as the inlet air dry-bulb temperature and wet-bulb temperature in the following calculations. On the other hand, air temperature and humidity at downstream of the outdoor coil were measured by a hygrosensor $\left( \pm 0.2{ }^{\circ} \mathrm{C}\right.$ and $\pm 1.0 \% \mathrm{RH}$ accuracy, respectively; Testo Hygrotest 650) located inside an air duct $700 \mathrm{~mm}$ at downstream of the outdoor coil outlet. To ensure the best possible measuring accuracy, the air wet-bulb temperature sensors positioned on the Side $\mathrm{C}$ of the outdoor coil were also calibrated using the hygrosensor. Furthermore, the air flow rate passing through the outdoor coil was measured by using a flow hood (of $\pm 3 \%$ accuracy) with a 16-point velocity grid located at the center of a $400 \mathrm{~mm} \times 400 \mathrm{~mm}$ air duct of $600 \mathrm{~mm}$ long, as shown in Fig. 5 .

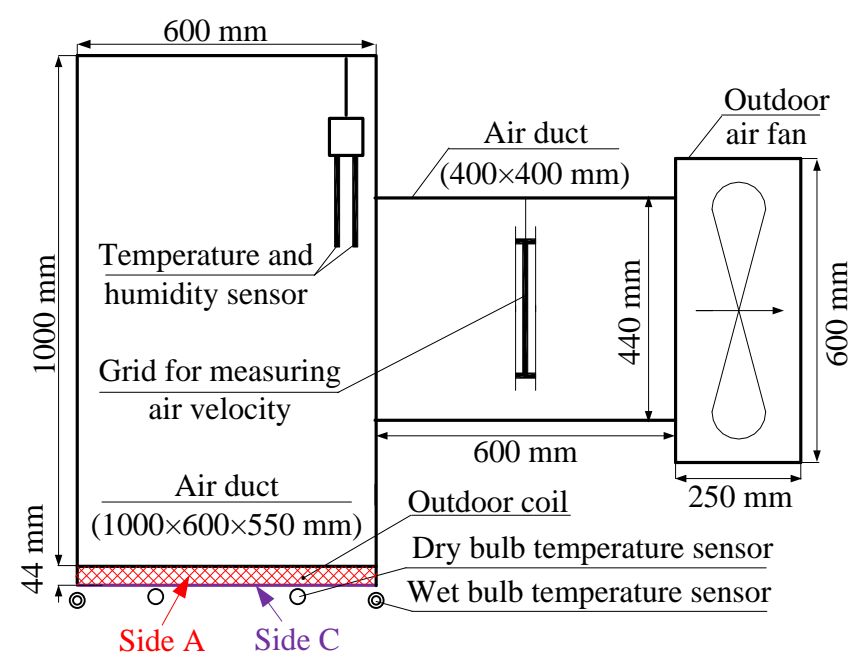

Fig. 5 The airside details of the outdoor coil in the experimental ASHP unit

Pre-calibrated K-type thermocouples were also used for measuring the temperatures of tube/coil and fin surfaces of the outdoor coil. Six were for measuring the refrigerant tube surface temperatures at both the inlets ( $T_{i}$ in Fig. 3$)$ and exits $\left(T_{e}\right.$ in Fig. 3$)$ of the three 
refrigerant circuits. Three were affixed on the fin surface at the center of each circuit. These fin surface temperature sensors located at the upward surface of the outdoor coil, the opposite side to Side C, so that the measured fin surface temperatures can avoid the effects of downwards flowing melted frost during defrosting. Furthermore, one more thermocouple was placed inside the water collecting cylinder to measure the temperature of the melted frost collected, as shown in Figs. 2 and 3. On the other hand, for the experimental ASHP unit, refrigerant pressures were measured using pressure transmitters (Danfoss Pressure Transmitter, Type AKS 32 and AKS 33) with an accuracy of $\pm 0.3 \%$ of full scale reading and refrigerant volumetric flow rate by a variable area flow meter with a reported accuracy of $\pm 1.6 \%$ of full scale reading (KROHNE VA Flowmeter, H250). All sensors and measuring devices were able to output direct current signal of 4-20 mA or 1-5 $\mathrm{V}$ which can be transferred to a data acquisition system (DAS) for logging and recording. The DAS collected and recorded all the measured data throughout both frosting and defrosting at an interval of $5 \mathrm{~s}$. In addition, during defrosting, photos for surface conditions of the outdoor coil were taken at an interval of $10 \mathrm{~s}$.

\subsection{Experimental procedures and conditions}

Prior to defrosting operation, the experimental ASHP unit was operated in the heating (frosting) mode for 60 minutes, at an outdoor frosting ambient temperature of $0.5 \pm 0.2$ ${ }^{\circ} \mathrm{C}$ (dry-bulb temperature) and $90 \pm 3 \%$ relative humidity, which was jointly maintained by the use of both experimental ASHP unit and the LGUs placed in the outdoor frosting space. During heating (frosting), air temperature inside the heated indoor space was 
maintained at $20 \pm 0.5^{\circ} \mathrm{C}$, which was jointly maintained by the use of both experimental ASHP unit and the existing air conditioning system. The experimental conditions are summarized in Table 2.

Table 2 Experimental conditions

\begin{tabular}{lllc}
\hline Item & Parameter & Value & Unit \\
\hline 1 & Air temperature in indoor heated space & 20 & ${ }^{\circ} \mathrm{C}$ \\
2 & Air temperature in outdoor frosting space & $0.5 \pm 0.2$ & ${ }^{\circ} \mathrm{C}$ \\
3 & Air relative humidity in outdoor frosting space & $90 \pm 3 \%$ & - \\
4 & Face velocity of outdoor coil & $1.3^{\mathrm{a}}$ & $\mathrm{m} \mathrm{s}^{-1}$ \\
5 & Face velocity of indoor coil at defrosting mode & 2.31 & $\mathrm{~m} \mathrm{~s}^{-1}$ \\
6 & Face velocity of indoor coil at heating (frosting) mode & 3.68 & $\mathrm{~m} \mathrm{~s}^{-1}$ \\
7 & Heating (frosting) operation duration & 60 & $\mathrm{~min}^{-1}$ \\
\hline
\end{tabular}

\footnotetext{
${ }^{\mathrm{a}}$ The average value during a heating (frosting) operation. During heating (frosting), the face velocity decreased due to frost growth.
}

Before defrosting was started, the compressor was firstly switched off. One minute after the shutdown of compressor, the four-way valve was switched to defrosting mode. Four seconds later, the compressor was powered on again manually, and a defrosting operation was started. Defrosting operation was also manually terminated when the tube surface temperature at the exits of the three refrigerant circuits in the outdoor coil all reached the preset-temperature, $24{ }^{\circ} \mathrm{C}$ in this study [15, 17-19]. To supply enough energy for defrosting and keep the ASHP unit work safely, the indoor air fan during defrosting 
Table 3 Measurement/calculation errors of system parameters

\begin{tabular}{|c|c|c|c|}
\hline Item & Parameter & Measurement/calculation error & Unit \\
\hline 1 & Air dry-bulb temperature at upstream of the outdoor coil & \pm 1 (K-type thermocouple) & ${ }^{\circ} \mathrm{C}$ \\
\hline 2 & Air wet-bulb temperature at upstream of the outdoor coil & $\pm 0.1(\mathrm{PT} 100$, class A) & ${ }^{\circ} \mathrm{C}$ \\
\hline 3 & Air temperature at downstream of the outdoor coil & \pm 0.2 (hygrosensor) & ${ }^{\circ} \mathrm{C}$ \\
\hline 4 & Air relative humidity at downstream of the outdoor coil & $\pm 1.0 \%$ (hygrosensor) & - \\
\hline 5 & Air flow rate passing through the outdoor coil & $\pm 3 \%$ (flow hood) & - \\
\hline 6 & Temperatures of tube/coil and fin surfaces & \pm 1 (K-type thermocouple) & ${ }^{\circ} \mathrm{C}$ \\
\hline 7 & Refrigerant pressure & $\pm 0.3 \%$ (pressure transmitters) & - \\
\hline 8 & Refrigerant volumetric flow rate & $\pm 1.6 \%$ (variable area flow meter) & - \\
\hline 9 & Mass of the melted frost collected & \pm 0.1 (weighing scale) & g \\
\hline 10 & Temperature of the melted frost collected & \pm 1 (K-type thermocouple) & ${ }^{\circ} \mathrm{C}$ \\
\hline 11 & Total energy supply for defrosting & $\pm 1 \%$ (calculated) & $\mathrm{kJ}$ \\
\hline 12 & Total energy consumption during defrosting & $\pm 1 \%($ calculated $)$ & $\mathrm{kJ}$ \\
\hline 13 & Defrosting efficiency & $\pm 0.15 \%$ (calculated) & - \\
\hline 14 & Defrosting evenness value & $\pm 5.9 \%$ (calculated) & - \\
\hline
\end{tabular}


remained operation at a lower speed. However, the outdoor air fan was turned off or turned to blowing at the opposite direction as the same air quantity in different experimental cases, which was controlled by the inverter (Model: KASUGA KIDEN INVERTER, KKVF-F204ESB). Table 3 summarizes the measuring accuracy for various sensors/instruments used in the experimental ASHP unit, and the calculated relative standard errors.

\subsection{Three experimental cases}

Series of experimental work using the experimental ASHP unit have been carried out to study the defrosting performance for an ASHP unit with a horizontally installed multi-circuit outdoor coil. In order to obtain meaningful experimental results, it was necessary to ensure that frost accumulated on the surface of the three circuits was even at first. For an ASHP unit with a multi-circuit outdoor coil, it is hard to make the frost evenly accumulated on the surface of the outdoor coil, as many parameters affect frosting performance [31]. However, in this study, modulating valves installed at the inlet refrigerant pipe to each circuit (as shown in Fig. 3) was deployed to vary the refrigerant flow to each circuit adjusted. Therefore, the frost accumulation on the surface of the three circuits was close to each other, with their biggest difference less than $10 \%[18,32,33]$. Secondly, to make the comparative study results meaningful, the frost accumulations in different cases should be close to each other. Therefore, in this study, frosting duration was fixed at 60 minutes, as listed in Table 2. The frost accumulations could be calculated 
with the total mass of the melted frost collected, with the water vaporized into the ambient air during defrosting neglected.

Fig. 6 shows the force analysis of retained water droplets on the surface of outdoor coil, on the conditions of (a) On side of single fin, (b) Between double fins, and (c) At the bottom of fins. Four types of force, gravity force $(\mathrm{G})$, fraction force $\left(\mathrm{F}_{\mathrm{f}}\right)$, normal force $(\mathrm{N})$, and surface tension $\left(\mathrm{F}_{\mathrm{s}}\right)$, would work on the water droplets. As the frost melted during defrosting, the melted frost would be held on the fin surface due to surface tension. As the water accumulated, the gravity effects of water increased. The melted frost would flow downwards when its gravity exceeded the maximum surface tension [34]. When a vertical outdoor coil was horizontally installed, blowing the melted frost maybe one of methods to increase the melted frost flowing away. As shown in Fig. 6, after the force of wind blowing $\left(\mathrm{F}_{\mathrm{w}}\right)$ added, the maximum surface tension was easily to be exceeded.

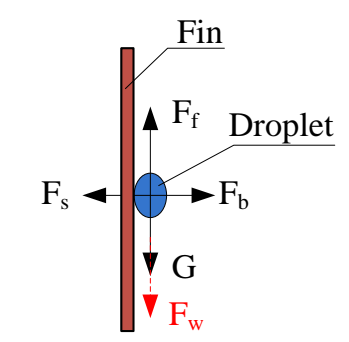

(a) On side of single fin

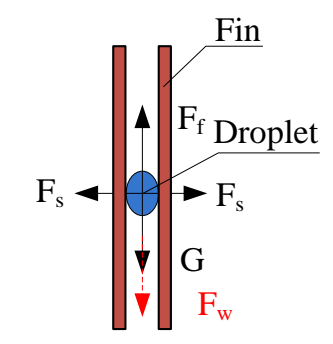

(b) Between double fins

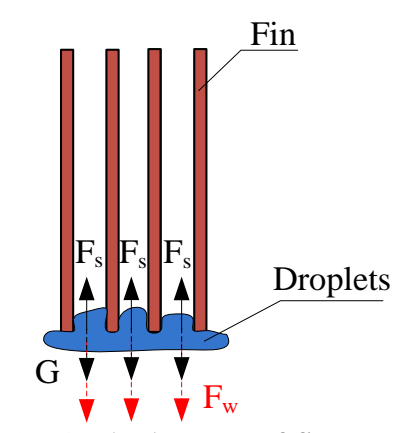

(c) At the bottom of fins

Fig. 6 Force analysis of retained water droplets on the surface of outdoor coil

Therefore, to comparatively and quantitatively study the defrosting performance of an ASHP unit having a horizontal multi-circuit outdoor coil, Case 1 and Case 2 were 
designed and carried out in this study. In the two cases, the outdoor coils were vertically and horizontally installed, respectively. Therefore, their experimental results could be meaningfully compared. Furthermore, to explore the effects of blowing the melted frost by reversing the outdoor air fan, Case 3 was also designed and conducted. In Case 3, the outdoor air fan was turned on and reversed blowing by control strategy adjustment during defrosting when the tube surface temperature of one circuit reached $3{ }^{\circ} \mathrm{C}$, and the blowing kept approximately $40 \mathrm{~s}$. In this method, the wind was expected to blow the melted frost away by destroying its surface tension. Therefore, the effects of wind blowing could be conducted by comparatively analysis the experimental results of Case 2 and Case 3. In addition, the melted frost kept vaporizing due to heating from fins during defrosting. Fig. 7 illustrates the mass transfer of the retained water during defrosting in the three cases, and all the experimental conditions and relative results listed in Table 4.

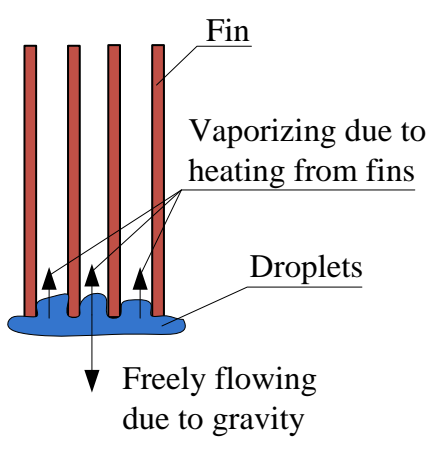

(a) Case 1 and Case 2

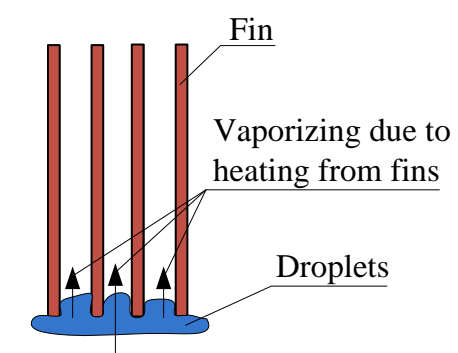

Freely flowing due to gravity and blowing the water away

(b) Case 3

Fig. 7 Mass transfer of the retained water during defrosting in the three cases 
Table 4 Experimental conditions and relative results in the three cases

\begin{tabular}{|c|c|c|c|c|}
\hline Item & Parameter & Case 1 & Case 2 & Case 3 \\
\hline 1 & Installation type of outdoor coil & Vertically installed & Horizontal installed & Horizontal installed \\
\hline 2 & Operation of outdoor air fan during defrosting & Turn it off & Turn it off & $\begin{array}{l}\text { Turn it on and reverse its } \\
\text { direction to blow the coil }\end{array}$ \\
\hline 3 & Defrosting duration & $186 \mathrm{~s}$ & $186 \mathrm{~s}$ & $204 s$ \\
\hline 4 & Total mass of the melted frost collected & $921 \mathrm{~g}$ & $948 \mathrm{~g}$ & $957 \mathrm{~g}$ \\
\hline 5 & Total mass of the retained water collected & $91 \mathrm{~g}$ & $566 \mathrm{~g}$ & $344 \mathrm{~g}$ \\
\hline 6 & Results shown in & $\begin{array}{l}\text { Figs. 8-10, 13; } \\
\text { Tables 5, } 7\end{array}$ & $\begin{array}{l}\text { Figs. 8, 9, 11, 14; } \\
\text { Tables 5-7 }\end{array}$ & $\begin{array}{l}\text { Figs. 8, 9, 12, 15; } \\
\text { Tables 5-7 }\end{array}$ \\
\hline
\end{tabular}




\section{Experimental results}

Six photographs illustrating the airside surface conditions of the outdoor coil at the start and end of defrosting in the three cases are shown in Fig. 8. As shown in Figs. 8(a1), 8(b1) and $8(\mathrm{c} 1)$, it is visually the same and evenly for the frost accumulated on the surface of the outdoor coil in the three cases, which met the requirements previously described in Section 2.3. As listed in Table 4, the frost accumulations, or the total mass of the melted frost collected, were $921 \mathrm{~g}$ in Case 1, $948 \mathrm{~g}$ in Case 2, and $957 \mathrm{~g}$ in Case 3, respectively. Their biggest difference, between Case 1 and Case 3, was just $36 \mathrm{~g}$, or about 3.76\%, which was small and acceptable in this study [18]. Meanwhile, as predicted, a lot of residual water retained over the outdoor coil downside surface when the defrosting operation terminated, especially in Case 2. As shown in Figs. 8(b2) and 8(c2), the melted frost retained on the downside surface over the horizontal multi-circuit outdoor coil in an ASHP unit due to surface tension during reverse cycle defrosting can be visually observed. Their differences on the mass of retained water could be found in the white dotted rectangles, as shown in Figs. 8(a2), 8(b2) and 8(c2). It is obviously that the retained water in Case 2 was much more than that in Case 3. In Case 1, there was nearly no melted frost found. The phenomenon met the mass of the retained water collected listed in Table 4, at $94 \mathrm{~g}$ in Case 1, $566 \mathrm{~g}$ in Case 2, and $344 \mathrm{~g}$ in Case 3, respectively. Therefore, similar mass of frost accumulations, frost evenly accumulated, and total mass of the retained water collected with obvious difference make this comparative study meaningful. 

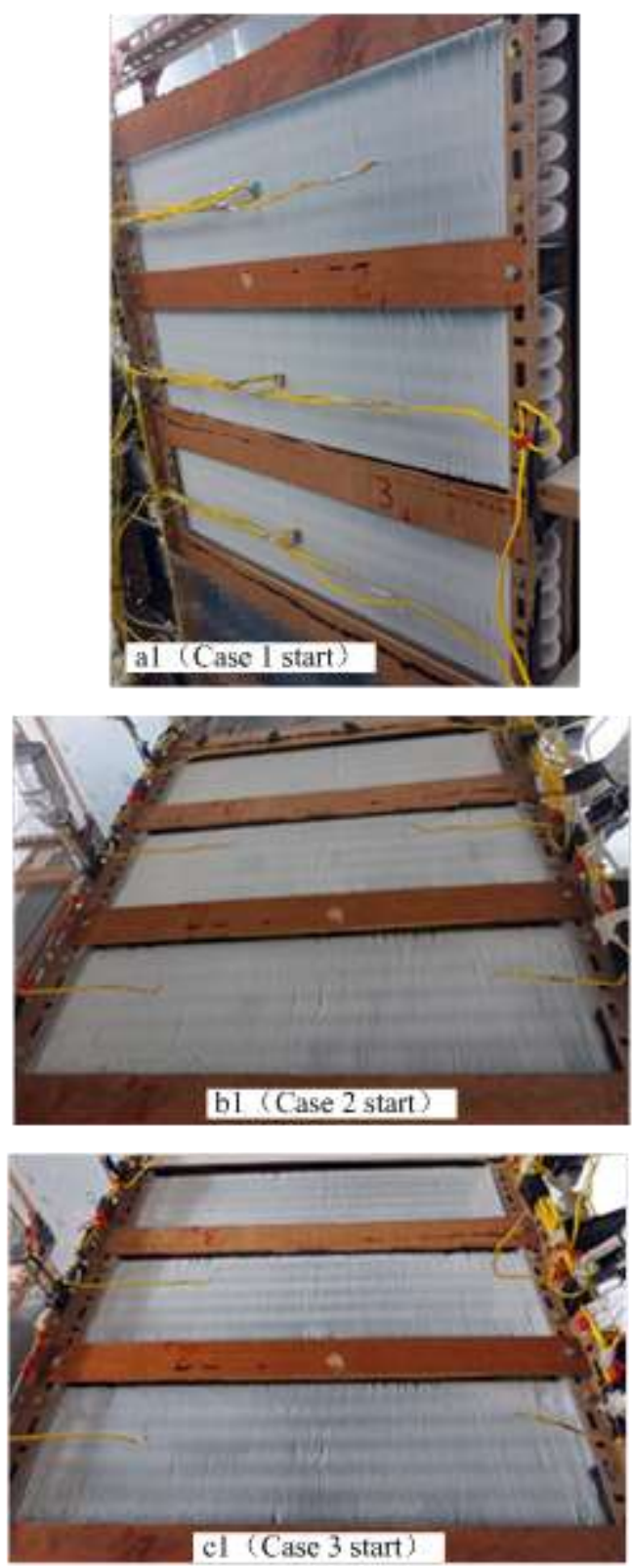
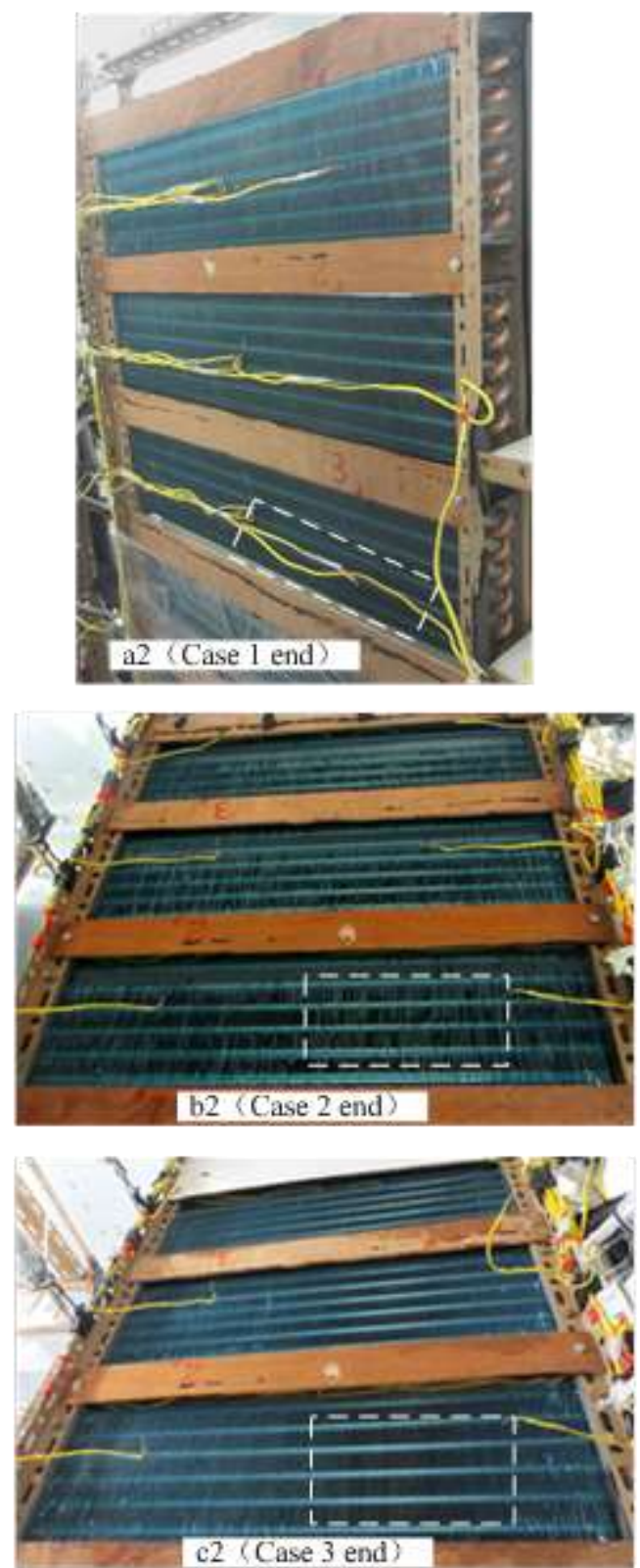

c2 (Case 3 end)

Fig. 8 Airside surface conditions of the outdoor coil at the start and end of defrosting in the three cases (six photographs)

To analysis the effects of wind blowing the melted frost, eight photographs illustrating the frost melting and downwards flowing process on the airside of the horizontal three-circuit outdoor coil in Case 2 and Case 3 are shown in Fig. 9. These photographs show the airside conditions of the outdoor coil from $60 \mathrm{~s}$ to $120 \mathrm{~s}$ into the defrosting 
operation. At this period, there was a lot of melted frost downwards flowing away from circuits in the two cases. Meanwhile, in Case 3, the fan was turned on at reversed direction, as well as a lot of melted frost was blowing away. As shown in Figs. 9(a1) and 9(b1), when the defrosting came to $60 \mathrm{~s}$, fin surface started directly contacting with the ambient air. However, there was still no melted frost flowing away from the circuit due to surface tension, as illustrated in Fig. 6. Also due to surface tension, after $60 \mathrm{~s}$ into the defrosting operation, the melted frost started flowing from side A to side B along the downside surface of each circuit, which was easily to be observed in Figs. 9(a2) and 9(b2). As the defrosting process went by, the mass of melted frost increased as its accumulation. As illustrated in Figs. 6 and 7, when the gravity direction total force of melted frost exceeded the maximum of the surface tension, the melted frost began downwards flowing from circuit to the water collecting tray. Therefore, from $60 \mathrm{~s}$ to $80 \mathrm{~s}$, there were few melted frost drops downwards flowing away from the circuit in the two cases. In addition, as shown in Figs. 9(a3) and 9(b3), at the positions indicated by the white arrows, a lot of melted frost kept downwards flowing to the water collecting tray. Especially at $100 \mathrm{~s}$ into defrosting, there was a lot of melted frost flowing away from the circuit. Meanwhile, due to the effects of wind blowing, more melted frost was flowing away from circuit in Case 3. When it came to $120 \mathrm{~s}$ into defrosting, there was still melted frost flowing away from circuits in Case 2. However, in Case 3, there was no any frost was flowing after the air fan turned off. Therefore, the effects of wind blowing on draining the melted frost were very obvious, which also met the total mass of the retained water collected listed in Table 4. 


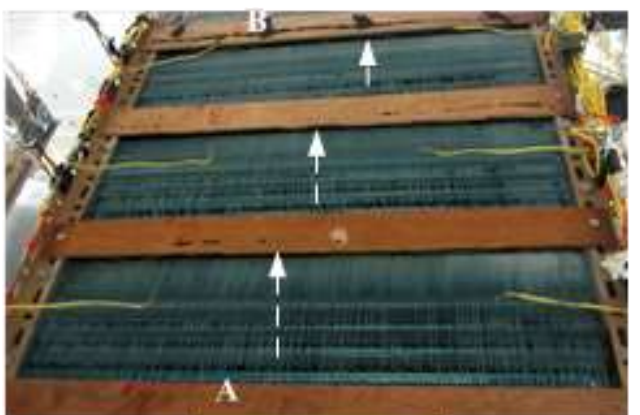

(al) 60 s Case 1

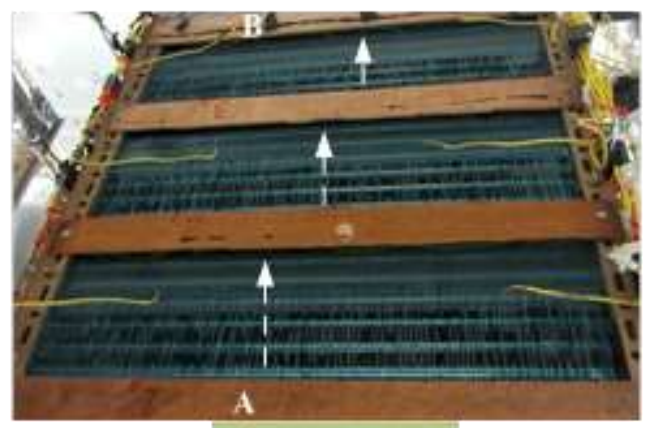

(a2) 80 s Case 1

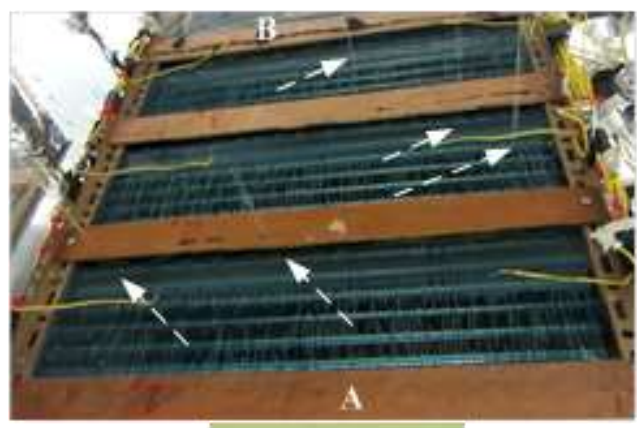

(a3) $100 \mathrm{~s}$ Case 1

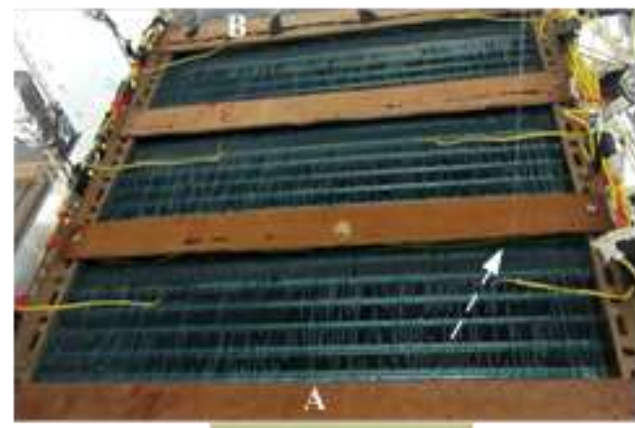

(a4) 120 s Case 1

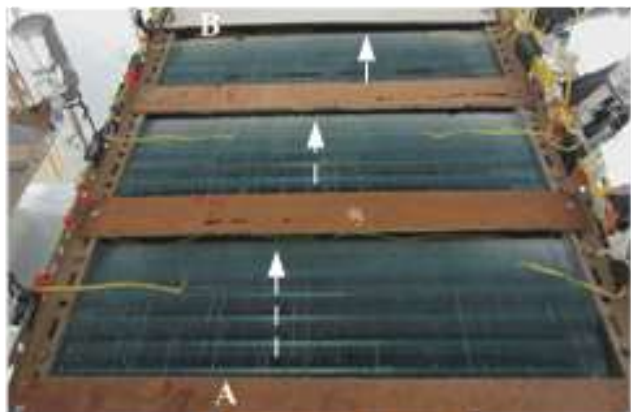

(bl) 60 s Case 2

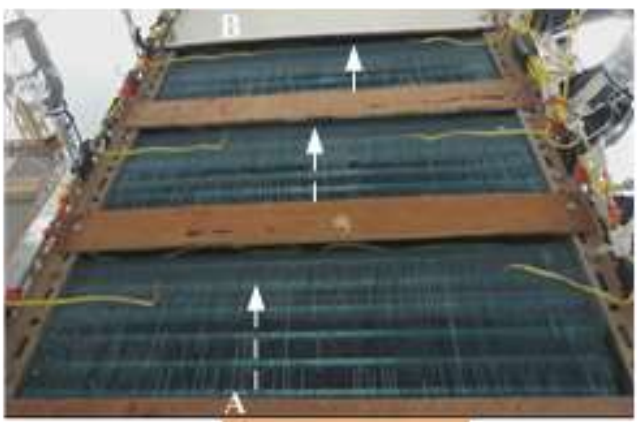

(b2) 80 s Case 2

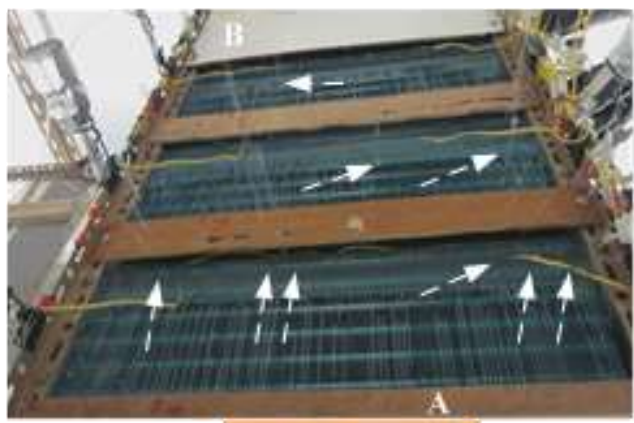

(b3) 100 s Case 2

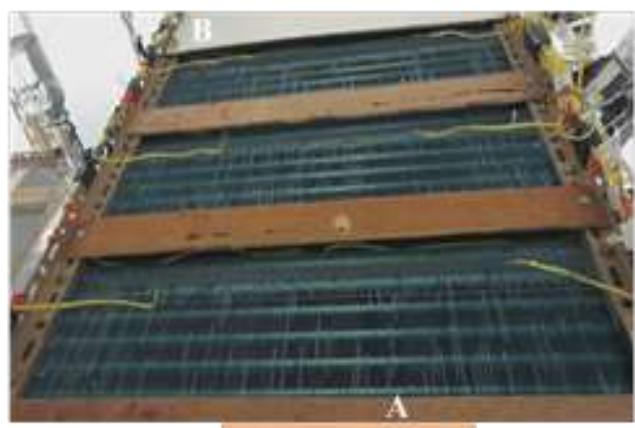

(b4) 120 s Case 2

Fig. 9 Airside surface conditions of the outdoor coil during defrosting in Case 2 and Case 3 (eight photographs) 
The measured operating performances of the experimental ASHP unit during defrosting, corresponding to the three experimental cases, are presented in Figs. 10-15. In all these figures, for their time (horizontal) axis, $60 \mathrm{~s}$ and $80 \mathrm{~s}$ are the chosen starting time in order to clearly show the temperature rise during defrosting. Figs. 10-12 present the measured tube surface temperatures at the exit of the three refrigerant circuits, and Figs. 13-15 show the measured fin surface temperatures at the center point of the three refrigerant circuits during defrosting. It is noted that the variation trends of these temperatures are similar to those reported by Qu and O’Neal [19, 20].

It can be seen from Fig. 10 that, in Case 1, tube surface temperatures of the three circuits remained around $0{ }^{\circ} \mathrm{C}$ during the first $100 \mathrm{~s}$, and started to rise steadily thereafter. Temperatures reached $24{ }^{\circ} \mathrm{C}$ at $172 \mathrm{~s}, 182 \mathrm{~s}$, and $186 \mathrm{~s}$, respectively [18]. As demonstrated that the negative effects of downwards flowing melted frost due to gravity, from $80 \mathrm{~s}$ to $186 \mathrm{~s}$, the relationship of tube surface temperatures kept at $T_{1}>T_{2}>T_{3}$ clearly. In addition, from $110 \mathrm{~s}$ to $150 \mathrm{~s}$, the order of curves was at $\mathrm{T}_{1}-\mathrm{T}_{2}>\mathrm{T}_{2}-\mathrm{T}_{3}$, because the mass of melted frost flowing into Circuit 3 was much more than that into Circuit 2. In this study, this case was mainly used to be compared with Case 2. 


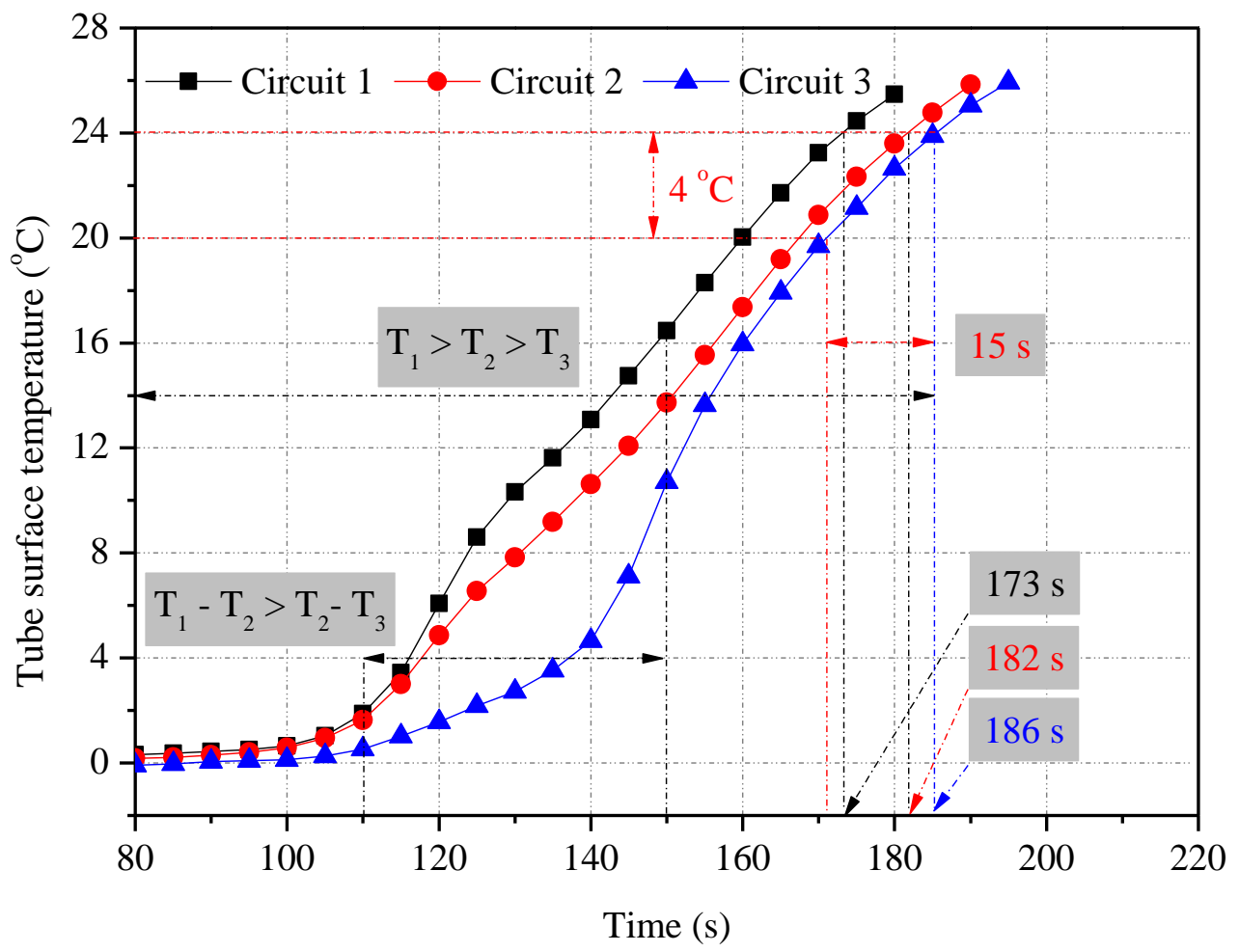

Fig. 10 Measured tube surface temperatures at the exits of the three refrigerant circuits during defrosting in Case $1[11]$

As shown in Fig. 11, in Case 2, tube surface temperatures of three circuits left $0{ }^{\circ} \mathrm{C}$ at 90 s, and started to rise steadily thereafter. From $80 \mathrm{~s}$ to $145 \mathrm{~s}$, the order of tube surface temperatures was at $T_{2}>T_{3}>T_{1}$. This is possible resulting from their uneven frosting accumulations and refrigerant distributions [32, 33]. The difference between three tube surface temperatures was small, with the biggest difference of $1.87^{\circ} \mathrm{C}$ at $110 \mathrm{~s}$. It is very obvious that the temperature curves steeply increased from $100 \mathrm{~s}$ to $130 \mathrm{~s}$, which met the Fig. 9 well. From $145 \mathrm{~s}$ to the end of defrosting, the relationship of tube surface temperatures kept at $T_{1}=T_{2}=T_{3}$. All the temperature curves for each circuit in Case 2 reached $24{ }^{\circ} \mathrm{C}$ at the same time, at $186 \mathrm{~s}$ into defrosting. That means the defrosting durations in Case 1 and Case 2 were the same. However, if their frost accumulations were 
the same, the defrosting duration in Case 2 may be shorter. Therefore, the defrosting performance would be better when the vertically installed multi-circuit outdoor coil changed vertically installed. In addition, compared with the trends of the tube surface temperature for the outdoor coil vertically installed in Case 1, as shown in Fig. 10 [18], the coincidence curves show that the negative effects of melted frost downwards flowing due to gravity could be eliminated after the outdoor coil horizontally installed.

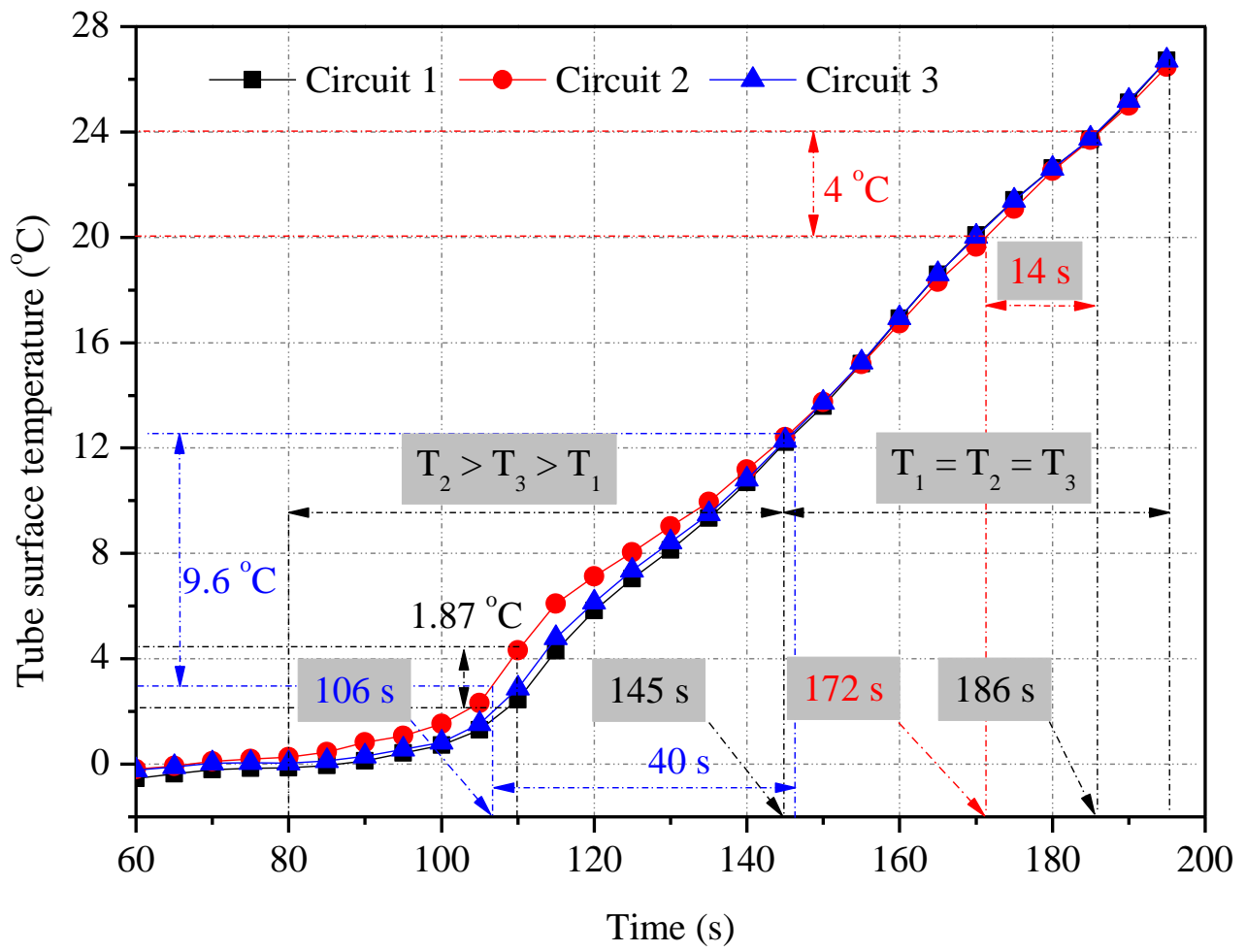

Fig. 11 Measured tube surface temperatures at the exits of the three refrigerant circuits during defrosting in Case 2

As shown in Fig. 12, the tube surface temperatures of the three circuits left $0{ }^{\circ} \mathrm{C}$ at approximately 100 s, and orderly reached $24^{\circ} \mathrm{C}$ at 199 s, 204 s, and 196 s, respectively. Obviously, compared with Case 2, the defrosting duration was prolonged. To clearly 
describe the effects of wind blowing, three stages were divided. From $80 \mathrm{~s}$ to $118 \mathrm{~s}$, named as Stage 1 in Case 3, the temperature curves' order kept at $T_{3}>T_{2}>T_{1}$. At Stage 2, from $118 \mathrm{~s}$ to $150 \mathrm{~s}$, the wind blowing showed negative effects on defrosting. Particularly, the temperature of Circuit 3 became lower than that of Circuit 2, and their order changed to $T_{2}>T_{3}>T_{1}$. The negative effects results from that the heat transfer was enhanced between the hot tube and fins in each circuit and the cold ambient air (around $0.5^{\circ} \mathrm{C}$ ). After $150 \mathrm{~s}$, at Stage 3, temperature of Circuit 3 returned to the highest one. The curves' order became to $T_{3}>T_{1}$, especially after $165 \mathrm{~s}$, was at $T_{3}>T_{1}>T_{2} . T_{3}$ was the highest one, which maybe result from the retained water left on the Circuit 3 was the least. And $\mathrm{T}_{2}$ was the smallest, which results from that the wind quality at the middle circuit of the outdoor coil was the highest. At this stage, temperature increased very quickly. This is resulting from most melted frost was drained. It could be found that, the turning point of Stage 2 and Stage 3 was at $150 \mathrm{~s}$, a little earlier than the time that air fan turned off, at 155 s. That means the positive effects of wind blowing were shown before the air fan turned off. Finally, compared with Case 2, it could be concluded that the operation of turning on the outdoor air fan and reversing the direction during defrosting could not decrease the energy waste fundamentally. 


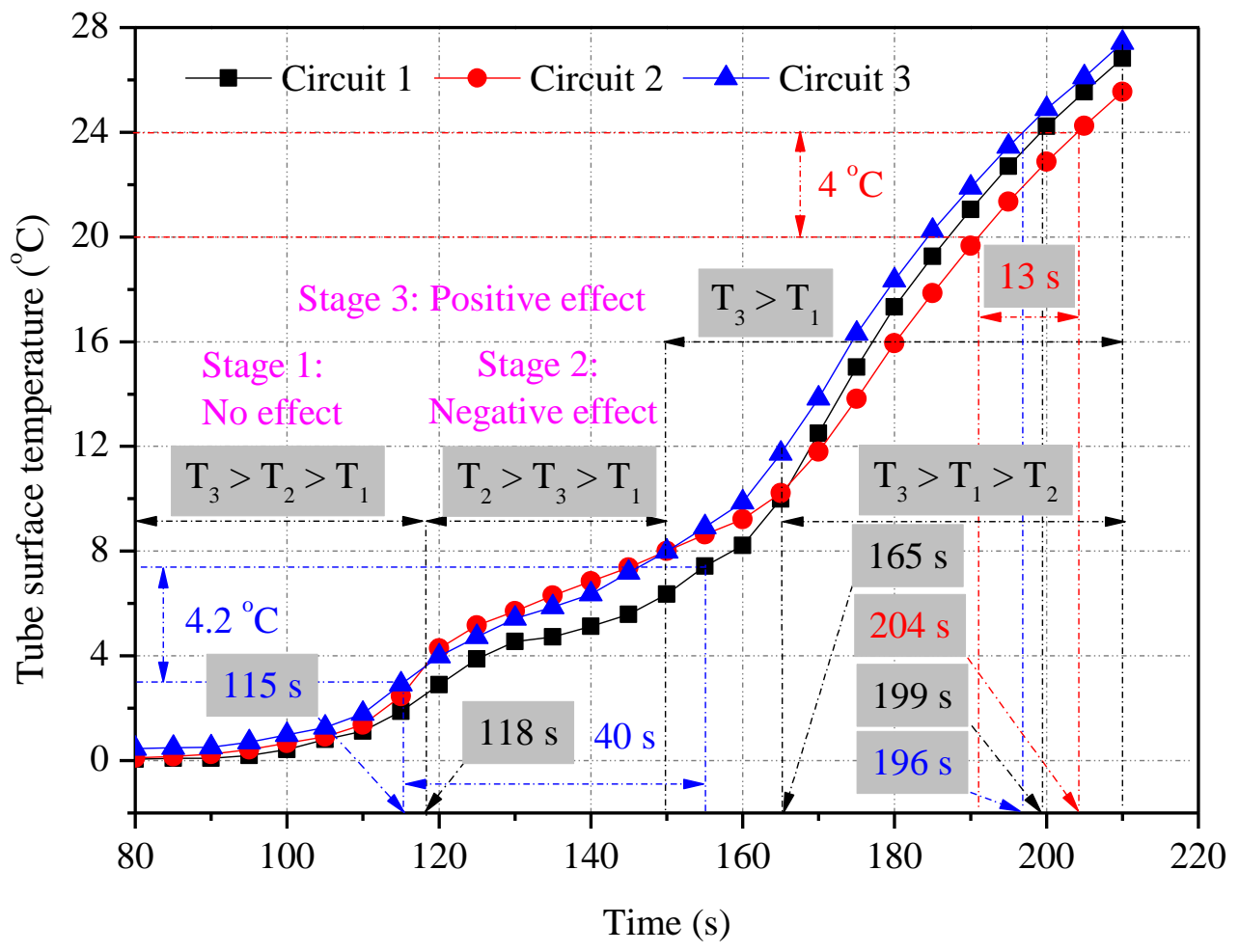

Fig. 12 Measured tube surface temperatures at the exits of the three refrigerant circuits during defrosting in

Case 3

As shown in Fig. 13, unlike tube surface temperatures, fin surface temperatures remained at $0{ }^{\circ} \mathrm{C}$ at the first $110 \mathrm{~s}$ into defrosting. The rise in fin surface temperature was later than that in tube surface temperature, because the tube was in direct contact with hot refrigerant, however, the fin indirectly in contact with refrigerant via tube. In Case 1, it took $185 \mathrm{~s}, 190 \mathrm{~s}$ and $195 \mathrm{~s}$ for the fin surface temperatures to reach $24{ }^{\circ} \mathrm{C}$ in the three circuits, respectively. During defrosting, fin surface temperature curves' order, the same as that of the tube surface temperature, kept at $T_{1}>T_{2}>T_{3}$ clearly. As demonstrated in the previous studies $[17,18]$, this also resulted from the negative effects of downwards flowing melted frost due to gravity. 


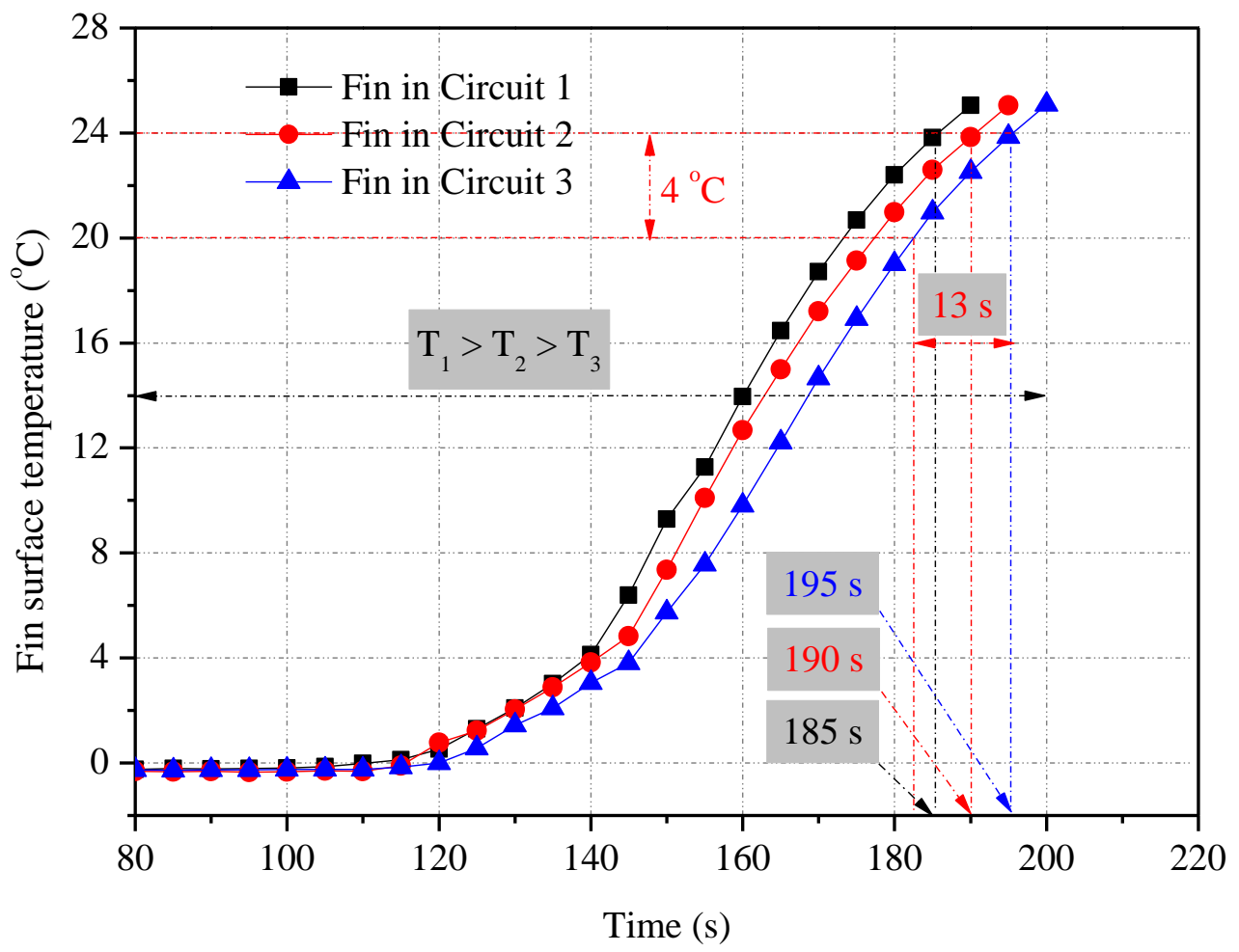

Fig. 13 Measured fin surface temperatures at the center of the three refrigerant circuits during defrosting in Case $1[11]$

Fig. 14 shows the measured fin surface temperatures at the center points of the three refrigerant circuits during defrosting in Case 2. From $60 \mathrm{~s}$ to $135 \mathrm{~s}, \mathrm{~T}_{2}$ was always the highest in the three circuits, which was also resulting from their uneven frosting accumulations and refrigerant distributions [32, 33]. At $95 \mathrm{~s}$, the relationship of temperature curves of Circuit 1 and Circuit 3 was changed from $T_{1}=T_{3}$ to $T_{1}>T_{3}$. This resulted from that the melted frost was downwards flowing, and the mass of flowing melted frost on the surface of Circuit 3 was less than that on Circuit 1 . After $135 \mathrm{~s}$, the three curves was coincidence, which also demonstrated that the negative effects of melted frost downwards flowing were eliminated when the vertical multi-circuit outdoor coil horizontally installed. Fin surface temperatures all reached $24{ }^{\circ} \mathrm{C}$ was at $188 \mathrm{~s}$, which was 
shorter than the duration in Case 1 about $7 \mathrm{~s}$, or $3.7 \%$ less. Therefore, it is further proved that the defrosting performance was better after the outdoor coil horizontally installed.

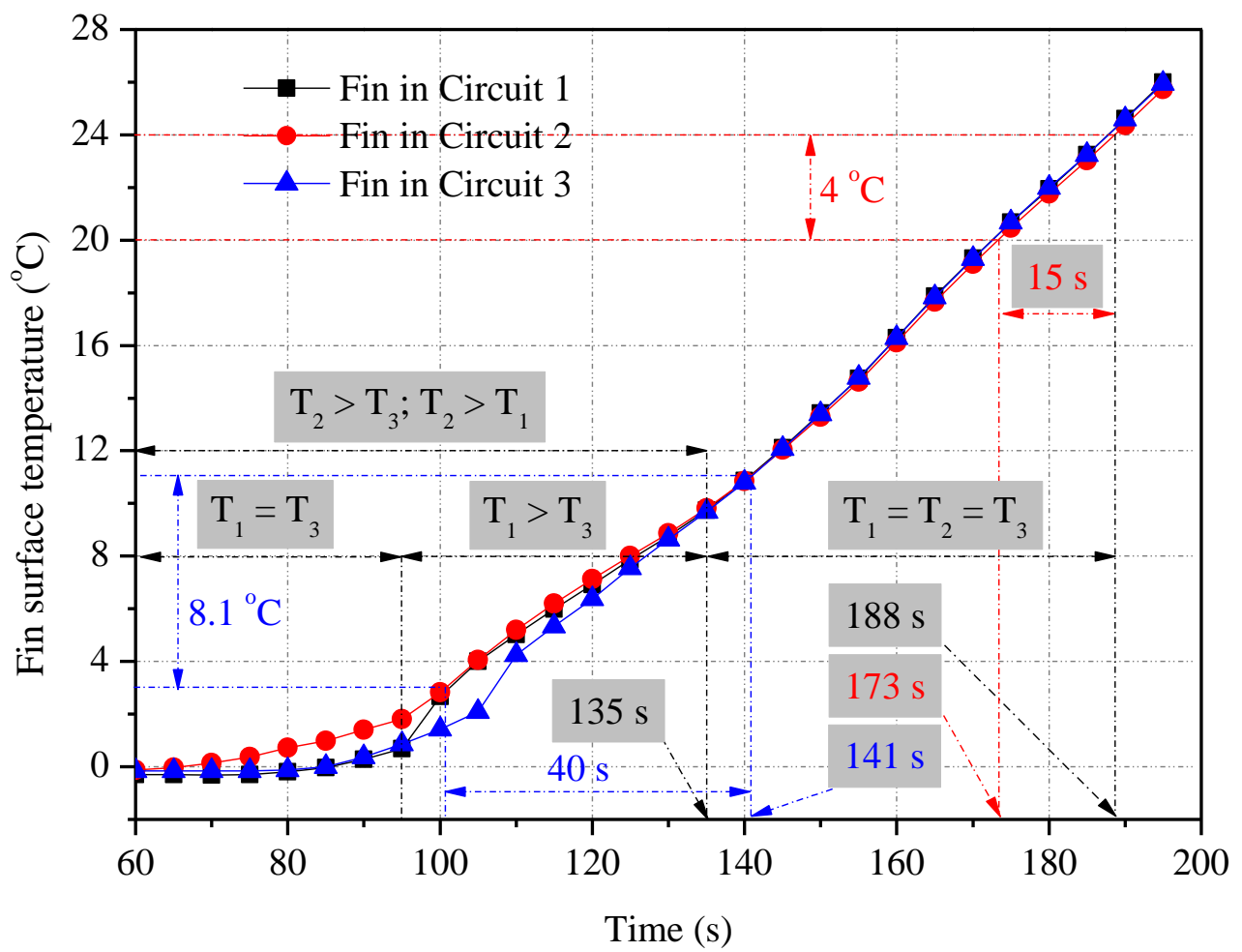

Fig. 14 Measured fin surface temperatures at the center of the three refrigerant circuits during defrosting in Case 2

As shown in Fig. 15, the fin surface temperatures of the three circuits left $0{ }^{\circ} \mathrm{C}$ at approximately $100 \mathrm{~s}$, and orderly reached $24^{\circ} \mathrm{C}$ at $205 \mathrm{~s}, 207 \mathrm{~s}$, and $205 \mathrm{~s}$, respectively. Obviously, compared with Case 2, this duration was not shorted, but prolonged. Therefore, it further proved the negative effects of wind blowing the melted frost during defrosting for an ASHP unit with a horizontally installed multi-circuit outdoor coil. The same as that show in Fig. 12, three stages were also clearly divided in the fin surface temperature curves. Obviously, at Stage 2, the temperature rose slowly, although there 
was a lot of melted frost was drained away by the wind blowing, as shown in Fig. 9. At stage 3 , especially at the later part in this stage, the temperature rose much steeply than that in Case 2, due to fewer melted frost remained on the surface of fins. Therefore, to improve the defrosting performance, the melted frost remained on the surface of fins should be drained clearly.

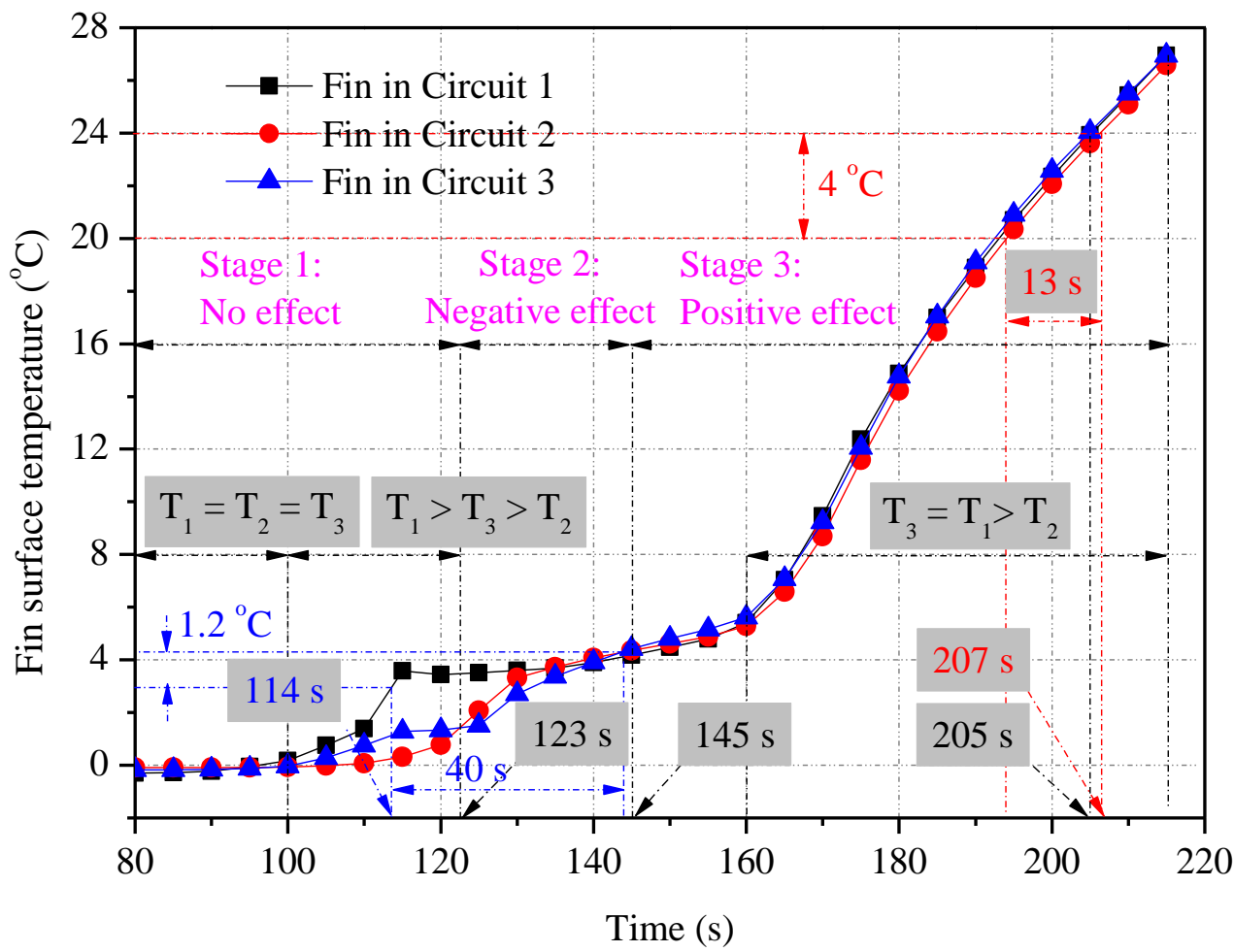

Fig. 15 Measured fin surface temperatures at the center of the three refrigerant circuits during defrosting in Case 3

\section{Discussions}

For an ASHP unit with a multi-circuit outdoor coil, to evaluate the energy consumption on heating ambient air due to waiting other circuit's tube surface temperature reaching the pre-set defrosting termination temperature, defrosting evenness value (DEV) was 
defined as the ratio of the minimum defrosting duration of circuit to the maximum one. Clearly, the higher the DEV was, more energy used for heating ambient air due to waiting other circuit terminating its defrosting could be saved.

$$
\mathrm{DEV}=\frac{\mathrm{A}}{\mathrm{B}} \times 100 \%
$$

A: The minimum defrosting duration for tube or fin of circuit;

B: The maximum defrosting duration for tube or fin of circuit.

Table 5 listed all the durations for tube and fin surface temperature of each circuit reaching $24{ }^{\circ} \mathrm{C}$, and the calculated DEVs for tube and fin in the three cases. The calculation errors of DEV were listed in Table 3. It could be found that, the DEVs for circuit are $93.01 \%$ for Case 1, 100\% for Case 2, and $96.08 \%$ for Case 3, respectively. And the DEVs for fin in three cases are $94.87 \%, 99.47 \%$, and $99.03 \%$, orderly. Obviously, although the fin surface temperature was later, the DEVs' orders for tube and fin were the same, at $\mathrm{DEV}_{2}>\mathrm{DEV}_{3}>\mathrm{DEV}_{1}$. In Case 2, the DEVs were highest, which means that there would be the least energy consumed on heating ambient air, with the shortest defrosting duration. Meanwhile, due to the lowest DEVs in Case 1, this part of energy wasted on heating ambient air was the most. Consequently, to improve the defrosting performance, the DEV should be higher. Meanwhile, DEV could be used as one index to evaluate the defrosting performance for an ASHP unit with a multi-circuit outdoor coil. 
Table 5 Durations for tube and fin and the DEVs in the three cases

\begin{tabular}{lllllll}
\hline Item & Parameter & Case 1 & Case 2 & Case 3 & Figs. & Unit \\
1 & Duration for tube of Circuit 1 & 173 & 186 & 199 & $10-12$ & $\mathrm{~s}$ \\
2 & Duration for tube of Circuit 2 & 182 & 186 & 204 & $10-12$ & $\mathrm{~s}$ \\
3 & Duration for tube of Circuit 3 & 186 & 186 & 196 & $10-12$ & $\mathrm{~s}$ \\
4 & DEV for tube surface temperature & $93.01 \%$ & $100 \%$ & $96.08 \%$ & - & - \\
5 & Duration for fin of Circuit 1 & 185 & 187 & 205 & $13-15$ & $\mathrm{~s}$ \\
6 & Duration for fin of Circuit 2 & 190 & 188 & 207 & $13-15$ & $\mathrm{~s}$ \\
7 & $\quad$ Duration for fin of Circuit 3 & 195 & 187 & 205 & $13-15$ & $\mathrm{~s}$ \\
8 & DEV for fin surface temperature & $94.87 \%$ & $99.47 \%$ & $99.03 \%$ & - & - \\
\hline
\end{tabular}

To clearly and comparatively study the effects of wind blowing melted frost, Table 6 listed all the different durations and their differences in Case 2 and Case 3. Starts of all the tube surface temperatures leaving $0{ }^{\circ} \mathrm{C}$ in the two cases were the same at $90 \mathrm{~s}$. However, starts of all the fin surface temperatures leaving $0{ }^{\circ} \mathrm{C}$ and starts of one tube and fin surface temperature reached $3{ }^{\circ} \mathrm{C}$ were a little earlier in Case 2. This maybe resulting from the frost accumulations in Case 3 was $9 \mathrm{~g}$ more than that in Case 2. Compared with Case 3, temperature of the tube and fin surface increased during the $40 \mathrm{~s}$, when the outdoor air fan reversed to blowing, were obvious much higher. It is further confirmed the negative effects of wind blowing during defrosting. Compared with Case 3, durations of the tube and fin surface temperatures all increased from $20{ }^{\circ} \mathrm{C}$ to $24{ }^{\circ} \mathrm{C}$ was much longer in Case 2. This resulted from less melted frost remained on the surface in Case 3. 
Table 6 Different durations and their differences in Case 2 and Case 3

\begin{tabular}{|c|c|c|c|c|c|c|}
\hline Item & Parameter & Case 2 & Case 3 & Difference $^{a}$ & Figs. & Unit \\
\hline 1 & Start of all the tube surface temperatures leaving $0{ }^{\circ} \mathrm{C}$ & 90 & 90 & 0 & 11,12 & $\mathrm{~S}$ \\
\hline 2 & Start of all the fin surface temperatures leaving $0{ }^{\circ} \mathrm{C}$ & 90 & 100 & 10 & 14,15 & $\mathrm{~s}$ \\
\hline 3 & Start of one tube surface temperature reached $3{ }^{\circ} \mathrm{C}$ & 106 & 115 & 9 & 11,12 & $\mathrm{~s}$ \\
\hline 4 & Start of one fin surface temperature reached $3{ }^{\circ} \mathrm{C}$ & 101 & 114 & 13 & 14,15 & $\mathrm{~s}$ \\
\hline 5 & Temperature of the tube surface increased during $40 \mathrm{~s}$ & 9.6 & 4.2 & -5.4 & 11,12 & ${ }^{\circ} \mathrm{C}$ \\
\hline 6 & Temperature of the fin surface increased during $40 \mathrm{~s}$ & 8.1 & 1.2 & -6.9 & 14,15 & ${ }^{\circ} \mathrm{C}$ \\
\hline 7 & Duration of the tube surface temperatures all increased from $20^{\circ} \mathrm{C}$ to $24{ }^{\circ} \mathrm{C}$ & 14 & 13 & -1 & 11,12 & $\mathrm{~s}$ \\
\hline 8 & Duration of the fin surface temperatures all increased from $20{ }^{\circ} \mathrm{C}$ to $24{ }^{\circ} \mathrm{C}$ & 15 & 13 & -2 & 14,15 & $\mathrm{~s}$ \\
\hline 9 & Defrosting duration (tube surface temperatures all reached $24{ }^{\circ} \mathrm{C}$ ) & 186 & 204 & 18 & 11,12 & $\mathrm{~s}$ \\
\hline 10 & Duration of the fin surface temperatures all reached $24{ }^{\circ} \mathrm{C}$ & 188 & 207 & 19 & 14,15 & $\mathrm{~s}$ \\
\hline
\end{tabular}

${ }^{\mathrm{a}}$ The difference of values in Case 2 and Case 3 is calculated with the following equation:

$$
\text { Difference }=\text { Value }(\text { Case 2) }- \text { Value }(\text { Case 3) }
$$


Compared with Case 2, durations of the tube and fin surface temperatures all reached 24 ${ }^{\circ} \mathrm{C}$ was longer in Case 3. This further confirmed the negative effects of wind blowing melted frost during defrosting.

As listed in Table 7, the energy supply, energy consumption and defrosting efficiency in three cases were also calculated $[18,32]$. In this experimental study, the total energy used for defrosting was $727.1 \mathrm{~kJ}$ in Case 1, but $697.9 \mathrm{~kJ}$ in Case 2, or 4.0\% less. In Case 3, the total energy consumed was $812.0 \mathrm{~kJ}$, or $16.3 \%$ more than that in Case 2. The defrosting efficiencies calculated for the three cases were calculated at $43.5 \%, 53.3 \%$ and $47.8 \%$, respectively. Compared the defrosting efficiency in Case 1 with that in Case 2, it could be concluded that the defrosting performance would be better when the outdoor coil horizontally installed. Also, it could be demonstrated that blowing the melted frost could not improve the defrosting performance, although the mass of retained water effectively decreased. Therefore, to destroy the surface tension and thus improving defrosting performance, fin structure adjustment and fin surface treatment maybe a direction of system optimization. 
Table 7 Energy supply, energy consumption, and defrosting efficiency in the three cases

\begin{tabular}{llllll}
\hline Item & Parameter & Case 1 & Case 2 & Case 3 & Unit \\
\hline 1 & The power input to compressor & 111.0 & 112.6 & 140.3 & $\mathrm{~kJ}$ \\
2 & The power input to indoor air fan & 6.3 & 1.7 & 1.6 & $\mathrm{~kJ}$ \\
3 & The power input to outdoor air fan & 0 & 0 & 7.2 & $\mathrm{~kJ}$ \\
4 & The energy from the indoor air & 609.9 & 538.6 & 663.0 & $\mathrm{~kJ}$ \\
5 & Total energy supply during defrosting & 727.1 & 697.9 & 812.0 & $\mathrm{~kJ}$ \\
6 & Energy consumption on melting frost & 307.6 & 323.3 & 313.0 & $\mathrm{~kJ}$ \\
7 & Energy consumption on vaporizing the & 55.0 & 48.9 & 66.0 & $\mathrm{~kJ}$ \\
& $\quad$ retained water & & & & \\
8 & Total energy consumption for defrosting & 362.6 & 372.2 & 379.0 & $\mathrm{~kJ}$ \\
9 & Defrosting efficiency & $43.5 \%$ & $53.3 \%$ & $46.7 \%$ & -
\end{tabular}

\section{Conclusions}

ASHP units have been widely applied in China due to their advantages including simple heat source, simple operation, high efficiency, and no pollution, etc. When frost forms and accumulates on the outdoor coil's surface, reverse cycle defrosting is periodical operated. In this experimental study, to decrease the flow path of downwards flowing melted frost due to gravity, the multi-circuit outdoor coil was changed to horizontally installed. In addition, the operation of reversing the outdoor air fan and blowing the remained water away was undertaken to decrease the total mass of remained water. Finally, the study results are reported, and the following conclusions received: 
1) When a vertically installed multi-circuit outdoor coil in an ASHP unit was changed to horizontally installed, the defrosting efficiency increased from $43.5 \%$ to $53.3 \%$, or at an increasing value of $9.8 \%$. Meanwhile, the negative effects of melted frost downwards flowing due to gravity were eliminated. The positive effects of multi-circuit outdoor coil horizontally installed on defrosting performance for an ASHP unit is obvious.

2) For an ASHP unit with a horizontal multi-circuit outdoor coil, when the outdoor air fan was used to blowing the melted frost during defrosting, total mass of the retained water collected decreased obviously, from $566 \mathrm{~g}$ to $344 \mathrm{~g}$, or $222 \mathrm{~g}$ less. However, the defrosting efficiency was not increased, but decreased from $53.3 \%$ to $46.7 \%$ due to the heat transfer enhanced between the hot coil and the cold wind. Therefore, destroying the surface tension to enhance the melted frost locally drainage, outdoor coil structure adjustment and fin surface treatment maybe a better choice.

3) To evaluate the energy consumption on heating ambient air due to waiting other circuit terminating its defrosting, DEV was innovatively defined and firstly used in this experimental study. The experimental results demonstrated that, to improve the defrosting performance, the DEV should also be improved. Therefore, there would be less energy consumed on heating ambient air to wait other circuit's defrosting termination. Furthermore, DEV was suggested to be used as an index to evaluate the defrosting performance of an ASHP unit with a multi-circuit outdoor coil. 
4) During an operational cycle of frosting-defrosting, for an ASHP unit, frosting duration is always much longer than the duration of defrosting. Consequently, frosting study accounts more important part in the studies of system performance improvement. Therefore, system frosting performance should also be explored for an ASHP unit with a horizontally installed outdoor coil, before a traditional vertical outdoor coil changed to horizontally installed.

\section{Acknowledgements}

The authors acknowledge the financial supports from The Hong Kong Polytechnic University, and the Guangdong University of Technology for the work reported in this paper.

\section{References}

[1] Moran MJ, Shapiro HN. Fundamentals of engineering thermodynamics. 3rd ed. Chichester: Wiley; 1998.

[2] Yamamoto T, Furuhata T, Arai N, Mori K. Design and testing of the organic Rankine cycle. Energy 2001; 26: 239-251.

[3] Quoilin S. Experimental study and modeling of a low temperature Rankine cycle for small scale cogeneration. Thesis, University of Liege; 2007.

[4] Wang F, Liang CH, Yang MT, Zhang XS. Preliminary study of a novel defrosting method for air source heat pumps based on superhydrophobic fin. Appl Therm Eng 2015; 90: 136-144.

[5] Ye XM, Xia XH, Zhang JF. Optimal sampling plan for clean development mechanism energy 
efficiency lighting projects. Appl Energy 2013; 112: 1006-1015.

[6] Ni L, Dong JK, Yao Y, Shen C, Qv DH, Zhang XD. A review of heat pump systems for heating and cooling of buildings in China in the last decade. Renew Energy 2015; 84: 30-45.

[7] Ameen FR, Coney JER, Sheppard CGW. Experimental study of warm-air defrosting of heat-pump evaporator. Int J Refrig 1993; 16: 13-18.

[8] Melo C, Knabben FT, Pereira PV. An experimental study on defrost heaters applied to frost-free household refrigerators. Appl Therm Eng 2013; 51: 239-245.

[9] Abdel-Wahed RM, Hifni MA, Sherif SA. Hot water defrosting of a horizontal flat plate cooling surface. Int J Refrig 1983; 6(3): 152-154.

[10] Tan HH, Xu GH, Tao TF, Sun XQ, Yao WD. Experimental investigation on the defrosting performance of a finned-tube evaporator using intermittent ultrasonic vibration. Appl Energy 2015; 158: $220-232$.

[11] Nobuki S, Katsuyoshi F, Sota S, Yusuke Y. Method for defrosting heat exchangers using an air-particle jet. Int J Refrigeration 2015; 60: 261-269.

[12] Kim J, Choi HJ, Kim KC. A combined Dual Hot-Gas Bypass Defrosting method with accumulator heater for an air-to-air heat pump in cold region. Appl Energy 2015; 147: 344-352.

[13] Wang W, Ma ZL, Jiang Y, Yang Y, Xu S, Yang Z. Field test investigation of a double-stage coupled heat pumps heating system for cold regions. Int J Refrig 2005; 28(5): 672-679.

[14] Payne V, O'Neal DL. Defrost cycle performance for an air-source heat pump with a scroll and a reciprocating compressor. Int J Refrig 1995; 18 (2): 107-112.

[15] Song MJ, Deng SM, Xia L. A semi-empirical modeling study on the defrosting performance for an air source heat pump unit with local drainage of melted frost from its three-circuit outdoor coil. Appl Energy 2014; 136: 537-547.

[16] Wang ZY, Wang XX, Dong ZM. Defrost improvement by heat pump refrigerant charge compensating. Appl Energy 2008; 85: 1050-1059.

[17] Song MJ, Pan DM, Li N, Deng SM. An experimental study on the negative effects of downwards flow of the melted frost over a multi-circuit outdoor coil in an air source heat pump during reverse cycle defrosting. Appl Energy 2015; 138: 598-604. 
[18] Song MJ, Deng SM, Pan DM, Mao N. An experimental study on the effects of downwards flowing of melted frost over a vertical multi-circuit outdoor coil in an air source heat pump on defrosting performance during reverse cycle defrosting. Appl Therm Eng 2014; 67: 258-265.

[19] Qu ML, Xia L, Jiang YQ, Deng SM. A study of the reverse cycle defrosting performance on a multi-circuit outdoor coil in an air source heat pump-Part I: experiments. Appl Energy 2012; 91: 122-129.

[20] O’Neal, DL, Peterson, KT, Anand NK, Schliesing JS. Refrigeration system dynamics during the reversing cycle defrost. ASHRAE Trans 1989; 95(2): 689-698.

[21] Dong JK, Deng SM, Jiang YQ, Xia L, Yao Y. An experimental study on defrosting heat supplies and energy consumptions during a reverse cycle defrost operation for an air source heat pump. Appl Therm Eng 2012; 37: 380-387.

[22] Adamson AW. Physical Chemistry of Surfaces. New York, NY: John Wiley; 1982.

[23] Li LT, Wang W, Sun YY, Feng YC, Lu WP, Zhu JH, Ge YJ. Investigation of defrosting water retention on the surface of evaporator impacting the performance of air source heat pump during periodic frosting-defrosting cycles. Appl Energy 2014; 135: 98-107.

[24] Kannadasan N, Ramanathan K, Suresh S. Comparison of heat transfer and pressure drop in horizontal and vertical helically coiled heat exchanger with $\mathrm{CuO} /$ water based nano fluids. Experimental Thermal and Fluid Science 2012; 42: 64-70.

[25] Yoon S, Lee SR, Go GH. Evaluation of thermal efficiency in different types of horizontal ground heat exchangers. Energy Buildings 2015; 105: 100-105.

[26] Simms RB, Haslam SR, Craig JR. Impact of soil heterogeneity on the functioning of horizontal ground heat exchangers. Geothermics 2014; 50: 35-43.

[27] Shen C, Jiang YQ, Yao Y, Deng SM. Experimental performance evaluation of a novel dry-expansion evaporator with defouling function in a wastewater source heat pump. Appl Energy 2012; 95: 202-209.

[28] Ciriello V, Bottarelli M, Di Federico V. Uncertainty-based analysis of variations in subsurface thermal field due to horizontal flat-panel heat exchangers. Procedia Environmental Sciences 2015; 25: $50-57$. 
[29] Qi GP, Jiang F. Numerical investigation on prevention of fouling in the horizontal tube heat exchanger: Particle distribution and pressure drop. Desalination 2015; 367: 112-125.

[30] Hambraeus K. Heat transfer of oil-contaminated HFC134a in a horizontal evaporator. Int J Refrig 1995; 18(2): 87-99.

[31] Yao Y, Jiang YQ, Deng SM, Ma ZL. A study on the performance of the airside heat exchanger under frosting in an air source heat pump water heater/chiller unit. Int J Heat Mass Transf 2004; 47: 17-18.

[32] Song MJ, Wang ZH, Mao N, Li Z, Chen Y. An experimental study on the uneven refrigerant distribution over a vertically installed multi-circuit outdoor coil in an air source heat pump unit during reverse cycle defrosting. Appl Therm Eng 2015; 91: 975-985.

[33] Kim JH, Braun JE, Groll EA. A hybrid method for refrigerant flow balancing in multi-circuit evaporators: Upstream versus downstream flow control. Int J Refrig 2009; 32(6): 1271-1282.

[34] Liang CH, Wang F, Lv Y, Wu CX, Zhang XS, Zhang YF. Experimental study of the effects of fin surface characteristics on defrosting behavior. Appl Therm Eng 2015; 75: 86-92. 